\title{
Assessment of curved FRP-reinforced masonry prisms: experiments and modeling
}

\author{
I. Basilio ${ }^{1}$, R. Fedele ${ }^{2}$, P.B. Lourenço ${ }^{3}$, G. Milani ${ }^{4 *}$ \\ ${ }^{1}$ Department of Construction and Health, Danish Building Research Institute (SBi) Aalborg \\ University - CPH A.C. Meyers Vænge 15, 2450 Copenhagen SV - Denmark \\ e-mail: ibasilios@gmail.com \\ ${ }^{2}$ Department of Civil and Environmental Engineering (DICA), Politecnico di Milano, Piazza \\ Leonardo da Vinci 32, 20133 Milan, Italy; e-mail: roberto.fedele@ polimi.it \\ ${ }^{3}$ Department of Civil Engineering, University of Minho, Campus de Azurem, Guimaraes, Portugal \\ e-mail:pbl@civil.uminho.pt \\ ${ }^{4}$ Department of Architecture, Built Environment and Construction Engineering (ABC), Politecnico di \\ Milano, Piazza Leonardo da Vinci 32, 20133 Milan, Italy; e-mail: milani@stru.polimi.it
}

Keywords: FRP, masonry curved structures, FE modeling, delamination.

Abstract. During the past decade, several approaches have been proposed to investigate the response of masonry structures strengthened by externally bonded Fiber Reinforced Polymer (FRP) reinforcements. Nowadays, regardless of the great efforts made, scarce information are available on the delamination behavior of reinforced curved substrates. An experimental and numerical study is presented herein, focusing on curved masonry prisms with a glass FRP strip. Both convex and concave configurations with a diverse curvature are considered for the specimens, constituted by four Portuguese bricks bonded by three joints of conventional mortar. The experimental data are interpreted in the light of fully threedimensional finite element simulations. Under the simplifying assumption of perfect adhesion, such advanced model allows to reconstruct local processes inside the masonry prisms, such as the damage distribution and the interface tractions, correlating them to the macroscopic response in terms of reaction force versus tangential slip. The effect of the geometrical curvature on the delamination response of the masonry prisms is critically and comparatively assessed by means of "step-by-step" numerical predictions together with a "direct" lower bound limit analysis approach. This topic is of paramount importance for structural engineering when dealing with masonry arches and double curvature structural elements.

\footnotetext{
*Corresponding author, e-mail: milani@stru.polimi.it, gabriele.milani@polimi.it, Phone: +39 0223994290.
} 


\section{INTRODUCTION}

During the past years Fiber Reinforced Polymers (FRP) are being widely used in strengthening and retrofitting interventions on masonry structures, mainly to increase the inplane shear resistance or to provide out-of-plane load bearing capacity. Composite materials can be advantageously applied at the intrados or at the extrados surface of flat and curved masonry structural elements, to prevent or delay collapse mechanisms and, consequently, to increase the overall safety factor, e.g. with respect to seismic events.

In particular, the mechanisms governing the interface bond have been extensively investigated [1]-[15]. While in the 1990s research was exclusively focused on reinforced concrete, in the last two decades the experimental and numerical literature extended also for masonry [16]-[40]. At present, mainly due to the technical progress in high strength adhesives, it can be stated that the delamination response of strengthened masonry is almost always dominated by the strength of the substrate [16]-[38], at least, when the influence of long term loading is not considered. Experimental studies demonstrate that debonding occurs because of the failure of the underlying masonry, with a further complication represented by mortar joints, which represent planes of weakness where cracks propagate preferentially even at low load levels on the FRP strip.

Despite the literature copiousness dealing with FRP reinforced masonry, there is still a lack of knowledge regarding the delamination of FRP strips from curved surfaces [36][39]. This topic is crucial to correctly predict the response of strengthened arches in the non-linear regime, particularly in those sections interested by the possible formation of plastic hinges and for anchoring purposes. At present, specialized codes of practice, see e.g. CNR DT 200R1 technical document [1], do not provide suggestions relevant to the reinforcement of a curved substrate, and, in particular, do not furnish indications on the possible reduction of the tangential strength due to the presence of normal stresses at the interface, let say on geometryinduced mixed mode loading conditions.

This study is the continuation of a research stream firstly initiated at the University of Minho [18][27][28], where two curved masonry prisms, one concave and the other convex, were subjected to single-lap shear tests. The aim of the present contribution is threefold: first, experimental evidences on curved reinforced prisms are outlined; subsequently, on this basis a 
three dimensional finite element model of the tested specimens is calibrated and validated; finally, a simple at-hand procedure, based on the lower bound theorem of limit analysis, is put at disposal for practitioners to predict the peak delamination strength of curved masonry elements.

Notation. Tensor notation is preferred for the damage model formulation, whilst vector notation is used elsewhere. Mechanical strengths in tension and compression, denoted by symbols $f_{t}$ and $f_{c}$, respectively, have not to be confused with the damage activation functions $f_{t}$ and $f_{c}$. Acronym FE will denote the Finite Element model.

\section{EXPERIMENTAL SET-UP AND CONSTITUENT PROPERTIES}

An experimental campaign was developed to assess the ultimate load and collapse mechanisms of reinforced masonry portions of arches, strengthened with FRP strips and subjected to standard delamination tests. The selected samples, see Figure 1, were constituted by four Portuguese Galveias clay bricks. This kind of bricks, produced by hand molding, exhibits higher absorption and porosity than modern standard bricks, and a low compressive strength, typical of ancient masonry buildings. For the readers' convenience the following reference values can be provided: bulk weight $\left(\mathrm{kg} / \mathrm{m}^{3}\right) 1740 ; 24 \mathrm{hrs}$ cold water absorption $11.2 \%$; porosity $20.9 \%$.

Bricks were suitably worked out along one direction to draw a curved shape, mimicking the portion of an arch. Thereafter, they were bonded by three joints of conventional mortar available in commerce. The resulting prism geometry exhibits flat external surfaces (over which all the bricks are aligned), except the strengthened surface, which possesses a curved shape with constant curvature radius $\mathrm{R}_{0}=760[\mathrm{~mm}]$. The tested portions of arches were $235 \times 130 \times 90 \mathrm{~mm}^{3}$ sized, and the GFRP strip had an anchorage (rectified) length equal to 150 $\mathrm{mm}$. Two geometries with the same curvature radius were considered [27] [28], one convex (hereafter labeled as $+\mathrm{R}_{0}$ ) and the other concave $\left(-\mathrm{R}_{0}\right)$. Hereinafter, the terms concave and convex have to be considered in the usual mathematical sense as profiles with a second order derivative positive or negative (when assuming axes as in Figure 2), respectively.

In Figure 2 the geometry and size of all the considered masonry prisms are illustrated, indicating also the location of the curvature center for the reinforced surfaces. Besides those tested in the experimental campaign, in fact, the response of specimens with different 
curvatures have been predicted by an accurate three dimensional FE model, accounting for damage processes in both mortar and bricks [21]-[23].

The experimental setup for single-lap shear test, sketched in Figure 1, was developed by Basilio [27] for an electro-mechanical Universal Instron testing machine, with a maximum capacity of $50 \mathrm{kN}$. The adapted device was specifically designed to avoid premature shear failure and to ensure an adequate stability of the test under displacement control. The samples were instrumented with LVDTs, providing also the feedback signal for the integral-derivative test control. Tested samples exhibited failure mechanism involving the masonry prism, with damage propagating deep inside the bulk material, for both the convex and concave configuration, as shown by post-mortem pictures in Figure 3.

Moreover, preliminary experiments were performed to assess the uniaxial behavior of single constituents. The experimental responses of mortar joints and bricks subjected to compression tests, see [27], are shown in Figure 4. Both brick and mortar exhibit similar peak strengths, and a marked post-peak, softening branch. For the readers' convenience, Table 1 indicates synoptically the material properties under compression. The dissipated energies were estimated as the area underlying the uniaxial constitutive plot in terms of stress and strains. In particular, dissipated energies in Table 1 were obtained by averaging those relevant to several experimental plots, as documented in Basilio [27]. For a critical comparison, the interested reader is forwarded to a comprehensive study carried out on Portuguese bricks [41].

\section{DAMAGE MODEL AND REGULARIZATION PROVISION}

To describe both brick and mortar response, recourse is made to an isotropic damage model originally presented in Comi \& Perego [45] for concrete, but applied also to possibly deteriorated dams and masonry elements [46][47]. The model was implemented in Abaqus ${ }^{\circledR}$ [48] commercial code with a suitable Fortran user defined subroutine Vumat [45] [46]. Only a few hints are provided herein, whereas the interested reader is forwarded to [21][22] for further details.

Each quasi-brittle constituent (brick and mortar) is described herein as an elasticdamageable material: both the shear and bulk elastic moduli, denoted by $G \equiv E /[2(1+v)]$ and $K \equiv E /[3(1-2 v)]$, respectively, are possibly deteriorated by damage. The governing equations are the following: 


$$
\begin{aligned}
& f_{t} \leq 0 \quad \dot{D}_{t} \geq 0 \quad f_{t} \dot{D}_{t}=0 \quad f_{c} \leq 0 \quad \dot{D}_{c} \geq 0 \quad f_{c} \dot{D}_{c}=0 \\
& f_{t}=J_{2}(\sigma)-a_{t 0} I_{1}^{2}(\sigma)+a_{t 1} h_{t}\left(D_{t}\right) I_{1}(\sigma)-a_{t 2} h_{t}^{2}\left(D_{t}\right) \\
& f_{c}=J_{2}(\boldsymbol{\sigma})+a_{c 0} I_{1}^{2}(\boldsymbol{\sigma})+a_{c 1} h_{c}\left(D_{c}\right) I_{1}(\boldsymbol{\sigma})-a_{c 2} h_{c}^{2}\left(D_{c}\right) \\
& h_{i}\left(D_{i}\right)=\left\{\begin{array}{cl}
1-\left(1-\sigma_{e i} / \sigma_{0 i}\right)\left(1-D_{i} / D_{0 i}\right)^{2} & D_{i}<D_{0 i} \\
{\left[1-\left(\frac{D_{i}-D_{0 i}}{1-D_{0 i}}\right)^{\mathrm{m}_{i}}\right]^{0.75}} & D_{i} \geq D_{0 i} \quad i=c, t
\end{array}\right.
\end{aligned}
$$

Symbols possess the following meaning: $\mathbf{1}=\delta_{i j}$ denotes the second-order identity operator; $\boldsymbol{\sigma}$, $\boldsymbol{\varepsilon}, \mathbf{S} \equiv \boldsymbol{\sigma}-(\operatorname{tr} \boldsymbol{\sigma} / 3) \mathbf{1}, \mathbf{e} \equiv \boldsymbol{\varepsilon}-(\operatorname{tr} \boldsymbol{\varepsilon} / 3) \mathbf{1}$ denote as usual the stress and strain tensors, and their deviatoric counterparts, respectively, being $I_{1} \equiv \operatorname{tr} \boldsymbol{\sigma}=\sigma_{i j} \delta_{j i}, J_{2} \equiv\left(\frac{3}{2} S_{i j} S_{j i}\right), \operatorname{tr} \boldsymbol{\varepsilon}=\varepsilon_{i j} \delta_{i j}$ tensor invariants; scalar variables $D_{t}$ and $D_{c}$ govern through Eq. (2) damage mechanisms in tension and compression, resp., giving rise to an effective damage $D \equiv 1-\left(1-D_{t}\right) \cdot\left(1-D_{c}\right)$ in Eq. (1); $f_{t}$ and $f_{c}$ denote the relevant damage activation functions; $a_{t 0}, a_{t 1}, a_{t 2}$ and $a_{c 0}, a_{c 1}, a_{c 2}$ in Eq. (2) are nonnegative material parameters, to be detailed later.

The current elastic domain is defined in the stress space by the inequalities $f_{t} \leq 0$ and $f_{c} \leq 0$ (see Eq. 2): its outer border is constituted by an hyperboloid and an ellipsoid, implicitly specified when strict equalities are considered for the above activation functions, respectively. The shape and location in the stress space of these geometric loci depend on the above parameters $a_{i j}(i=c, t ; j=0,1,2)$, which have to satisfy consistency conditions [45], and on the current value of the monotonically increasing damage variables $\left(\dot{D}_{i} \geq 0\right)$ through functions $h_{i}$ specified in Eq. (3).

Hardening/softening function $h_{t}$ and $h_{c}$ appearing in Eqs. (2) and (3) depend: in the hardening branch, on parameters $\sigma_{e i} / \sigma_{0 i}$ and $D_{0 i}$, namely on the ratio between the stress at the elastic limit and the uniaxial strength, and on the damage level at peak under uniaxial 
conditions, respectively; in the descending, softening branch, uniquely on parameter $\mathrm{m}_{i}$ $(i=c$ or $t)$.

Fracture energy regularization. The present FE implementation includes a specific strategy, simple but effective, for fracture energy regularization. At each integration point, parameter $\mathrm{m}_{i}(i=t, c)$, governing the post peak branch of the softening function $h_{i}$ in Eq. (3), ensures that the dissipated energy $G_{i}(i=t, c)$ does not vary from one element to another. To this purpose, at the beginning of each analysis a database is generated depending on the adopted material parameters (separately for each constituent). Several uniaxial stress-strain plots are drawn at varying the post-peak parameter $m_{i}$ inside a reasonable range, and a suitable set of specific energies $g_{i}\left(\mathrm{~m}_{i}\right)=\int_{0}^{+\infty} \sigma d \varepsilon$ are simply derived by quadrature. In practice, separately for tension and compression $(i=t, c)$, the forward function $\mathrm{m}_{i} \rightarrow g_{i}\left(\mathrm{~m}_{i}\right)$ is sampled inside a reasonable interval, and the inverse relationship $g_{j} \rightarrow \mathrm{m}_{j}$ can be easily estimated once for all by interpolating values available in the database. The specific (for unit volume) energy to be dissipated locally should satisfy the relationship $g_{i}\left(\mathrm{~m}_{i}\right)=G_{i} / l_{\mathrm{ch}}$, where the characteristic length represents the width of the crack brand front, herein assumed as $l_{\mathrm{ch}} \equiv \sqrt[3]{V_{\mathrm{el}}}$, being $V_{\mathrm{eq}}$ the element volume. Values of parameter $\mathrm{m}_{i}(i=t, c)$ so achieved at each integration point, separately for each constituent, can be stored in memory and remain unchanged throughout the analysis. The values of $\mathrm{m}_{j}$ to be exploited in the database depend on the range of characteristic lengths in the adopted FE discretization, by which fracture energy $G_{i}$ is scaled, namely belong to the interval $\left[\min l_{\mathrm{ch}}, \max l_{\mathrm{ch}}\right]$. For the problem at hand, twelve values $\mathrm{m}_{j}$ were considered.

In Figure 5, the simulated response of the brick material under uniaxial tension is shown, with the regularized post-peak softening branch varying as a function of the element side. As expected, when the element size decreases, the dissipated energy $g_{t}$ (herein represented by the area underlying the plot) increases, and the response exhibits an augmented ductility. On the contrary, if the element side is excessively large, snap-back phenomena may occur. The overall distribution of the post-peak parameters $\mathrm{m}_{i}(i=t, c)$ estimated by the 
above procedure for each constituent inside the adopted discretization, is shown in Figure 6-a and $-b$, with reference to the dissipated energy in tension and compression, respectively.

Calibration/validation of model parameters. Simple analytical formulae are provided in Comi \& Perego [45], allowing one to relate the model parameters $a_{i j}(i=c, t ; j=0,1,2)$ entering the above activation functions, Eq. (2), with the mechanical quantities used for design and engineering practice. Model parameters governing the compressive response of both mortar and brick were derived on the basis of uniaxial compression tests preliminarily performed on the single masonry constituents, as detailed by Basilio [27] and summarized in Table 2. On the basis of suggestions available in the literature (see also [29],[41]-[44]), the tensile strengths were assumed according to the relationship $\mathrm{f}_{\mathrm{t}} \approx 5 \% \mathrm{f}_{\mathrm{c}}$ [22]. Values of dissipated energies $G_{t}$ were tuned to fit the macroscopic response of the prisms.

The initial elastic domains for both mortar and brick materials are drawn in the Haar Westergaard space in Figure 7-a and Figure 7-b, respectively, under plane-stress conditions. Under uniaxial compression, the experimental response for brick and mortar and their simulated counterparts are shown in Figure 8-a and Figure 9-a, respectively. For the user convenience, also the response in tension predicted by the adopted damage model is visualized (subfigures $b$ ).

In the FE model GFRP strip ( $1 \mathrm{~mm}$ thick) was assumed to be perfectly bonded to the substrate, and to behave as an isotropically elastic material with Young Modulus equal to 20 GPa and Poisson's ratio to 0.20. In the authors' experience, values provided for the GFRP thickness and for the estimated Young modulus should be regarded as the effective or apparent thickness/stiffness of a composite material including several layers of grout and adhesive suitably (manually, by a roller) superimposed to each other according to a well defined protocol, and during curing subjected to hardening and shrinkage. Assuming an elastic response for the FRP composite, a micromechanical approach would lead to estimate local stresses in the reinforcement constituents, see Basilio et al. [18]. By means of a suitable choice of a micromechanical model for the composite, see Sejnoha \& Zeman [49], it is always possible to check whether the local stresses are indeed found in the allowable limits, see Dvorak \& Sejnoha [50] [51]. 


\section{FINITE ELEMENT ANALYSES OF CURVED PRISMS}

Masonry prisms tested during the experimental campaign, with a constant curvature radius $\pm \mathrm{R}_{0}$ over the reinforced surface, were discretized by finite elements, as shown in Figure 10. A comparison between the overall responses derived from the experiments, in terms of reaction force versus prescribed displacement, and their computed counterparts is given in Figure 11, for both the concave and convex case. As expected, concave configuration implies higher peak loading. Conversely, experimental data exhibit a quite marked scatter in the convex case, with peak loads sometimes higher with respect to those relevant for the concave case.

The damage distributions at increasing displacements are represented in Figure 12 and Figure 13 for the convex and concave case, respectively. As it can be noted, damage propagates deeply inside masonry, as confirmed by post-mortem pictures of the tested prisms in Figure 3. Moreover, the mechanical properties of the adopted mortar, close to the brick's ones, are responsible for the extensive diffusion of damage inside bricks during delamination tests. In the presence of weak joints, instead, damage localizes closely to the strip attachment, see e.g. Fedele \& Milani [21][22].

Once that the FE model was calibrated and validated by the available tests on prisms with assigned curvature radius (referred to as $\mathrm{R}_{0}$ ), analyses were extended till to include different geometries. In fact, two additional convex $\left(+1.25 \mathrm{R}_{0},+0.75 \mathrm{R}_{0}\right)$ and two concave ($1.25 \mathrm{R}_{0}$ and $-0.75 \mathrm{R}_{0}$ ) curvature radii were considered for the prisms, as schematically indicated in Figure 2. In addition, a convex geometry with a very large curvature radius $(+5$ $\mathrm{R}_{0}$ ) was finally modeled to approximate a flat reinforcement. As a consequence, the total amount of geometries considered for the computer simulations is equal to seven, namely three for both convex and concave configurations, plus the approximated flat configuration as a reference. Therefore, the numerical campaign made available a wider set of data, to better investigate the dependence of delamination strength on the reinforced prism curvature.

The overall responses computed by the finite element model at varying the curvature radius are synoptically visualized in Figure 14 . As it can be observed for the convex case $\left(+0.75 \mathrm{R}_{0}\right.$, $+\mathrm{R}_{0},+1.25 \mathrm{R}_{0}$ ), an increase of the curvature radius (or a decrease of curvature, resp.) results into an overall response with a higher peak strength and a larger ductility. For the concave case (-0.75 $\left.R_{0},-R_{0},-1.25 R_{0}\right)$, instead, an opposite trend is experienced, namely an increase (in 
modulus) of curvature radius implies a decrease of the peak strength and a more marked overall brittle response. The flat case represents in a sense the separation element behavior between convex and concave samples and their response, rigorously recovered when $R_{0} \rightarrow \infty$, and herein approximated by a convex prism with radius $5 \mathrm{R}_{0}$.

The increase and decrease of the peak load with the curvature radius, for convex and concave prisms respectively, should be regarded as a systematic trend and can be justified investigating the stresses acting over the GFRP-masonry prism interface. In fact, stress tensor inside the reinforcement can be extrapolated to the interface nodes, and normal and tangential tractions acting over the joint easily derived according to Cauchy's tetrahedron theorem.

Critical observations concerning the numerical results can be outlined as follows.

(1) Averaged values (over the CFRP-masonry joined area) for shear and normal stresses over the reinforcement-masonry interface at the peak loads, say $\left\langle\sigma_{n}\right\rangle$ and $\langle\tau\rangle$, were evaluated by suitable post processing of FE results, and visualized in the Mohr plane, see Figure 15. A marked trend with respect to the curvature radius of the interface can be noted. The same results are differently arranged in Figure 16, in terms of the mean normal (subfigure a) and tangential (subfigure b) stress components acting over the FRP-masonry interface, as a function of normalized curvature radius $\mathrm{R} / \mathrm{R}_{0}$. As it can be observed, convex specimens possess a positive average normal stress $\left\langle\sigma_{\mathrm{n}}\right\rangle>0$, which induces premature separation between the adherents (masonry and reinforcement). Such positive stress is responsible for the lower average shear strength of the interface. The average normal stress $\left\langle\sigma_{n}\right\rangle$ increases with the curvature (and decreases with the curvature radius): its trend can be satisfactorily fitted by a cubic spline, as shown in Figure 16.

When dealing with the concave specimens, a meaningful negative normal stress $\left\langle\sigma_{n}\right\rangle<0$ (up to around $0.1 \mathrm{MPa}$ ) acts at the interface, which prevents adherents from separating. Such normal stress decreases -in absolute value- when the curvature radius (in absolute value) increases. The flat case exhibits, as expected, an almost zero mean normal stress $\left\langle\sigma_{n}\right\rangle \approx 0$ (see the cubic interpolation reported in Figure 16), and locally pure mode II conditions are recovered. Results reported in Figure 15 may be extremely useful even to practitioners interested in a correct evaluation of the peak delamination strength in masonry arches with assigned curvature radius. It is worth emphasizing that specialized codes of practice, see for instance 
CNR-DT 200 [1] Italian code on FRP reinforcement, provide scarce information on this crucial issue.

(2) In Figure 17 the local stresses acting over the FRP-masonry joint at the peak load, predicted by the FE model, are visualized for the tested convex geometry. The same results are replicated in Figure 18 for the concave prism. Similar results are met also for the modified curvatures, for brevity not reported herein. Figure 19 shows the peak normal (a) and tangential (b) stresses acting on the FRP-masonry joint, as a function of the normalized curvature radius of the interface. Moreover, in agreement with trends already observed for the mean stress values, a meaningful variation of the peak stresses occurs when passing from negative to positive curvatures (from concave to convex configurations, resp.), which is at the origin of the overall extra-resistance of the reinforcement on concave specimens.

(3) It is worth emphasizing that, since brick and mortar possess herein similar tensile strength, damage diffuse extensively on both the prism constituents, concentrating on parallel (skew) bands even at low levels of the external loading, see also Figure 12 and Figure 13. Closely to such damaged bands, stresses are obviously not transmitted anymore, whereas high peak loads are still present on the undamaged zones. This is the main reason of the highly oscillating stresses at the interface predicted by FE analyses. A more complex formulation would be required, allowing for both interface and bulk damage, with a smooth transition.

\section{COMPARATIVE ASSESSMENT WITH AN ANALYTICAL LIMIT ANALYSIS APPROACH}

Some highlights on the effectiveness of the proposed study can be provided by a simplified, analytical limit analysis approach.

Limit analysis is a relatively simple, classic tool that may be easily coupled with FEM (see for a detailed analysis of the mathematical approach used Anderheggen \& Knopfel [54], Poulsen \& Damkilde [55] and for an application to masonry Milani et al. [56]). It allows a fast evaluation of collapse loads, failure mechanisms and, at least on critical sections, stress distribution at collapse.

The FEM implementation requires always the solution of a linear programming problem and, therefore, requires in general the utilization of sophisticated optimization routines. In what follows, a coarse discretization of the problem is adopted, which allows to reduce the problem 
of estimating the collapse load of the structure, to a linear programming problem with a single variable and with inequalities constraints only.

In particular, the 2D (plane stress) lower bound discretization shown in Figure 20 is adopted for the curved prisms in point. It is constituted by 11 constant stress (CST) triangular elements, whilst mortar joints are reduced to zero-thickness interfaces and FRP strip are modeled as rods subjected exclusively to axial forces and tangential actions along the axis of the FRP simulating the bond on the prism.

Boundary conditions are selected such as to mimic the actual b.c. used in the experiments.

As detailed in Figure 20, variables involved in the limit analysis problem are: (a) three stress components for each CST element (say $\sigma_{x x}^{(i)}, \sigma_{y y}^{(i)}, \sigma_{x y}^{(i)}$, indicating respectively horizontal, vertical and tangential stress inside the $i$-th element); (b) two stresses for each FRP/brick interface (denoted as $\sigma^{(j)}$ and $\tau^{(j)}$, where $j$ is the interface number, $\sigma$ and $\tau$ indicate the normal and tangential stress, resp.); (c) three axial stresses for the FRP strip (denoted as $\lambda$, the load multiplier to maximize, $\lambda_{2-3}$ and $\lambda_{1-2}$ ). The total number of unknowns governing the optimization problem is therefore equal to 42. Equality constraints to be imposed in the mathematical programming problem, in which the loading multiplier is maximized, are as follows: (1) equilibrium constraints at the interface between contiguous triangular elements, (2) equilibrium constraints at the interfaces between blocks and FRP, (3) FRP internal equilibrium constraints and (4) stress boundary conditions.

The first set of equality constraints, above labeled as a), is constituted by 24 linear equations, since the interfaces between triangular elements are 12, and equilibrium must be imposed on both normal and tangential components of stress vector acting on the interface. The second and third set of equalities, above labeled as b) and c), are constituted by 12 equations (three interfaces and three FRP elements were included, and two equilibrium equations must be written for each interface / element), whereas to prescribe boundary conditions 5 additional equations are required. In total, 41 equality constraints should be properly considered in Figure 20. It can be easily checked that the 41 equations derived from equilibrium and boundary conditions on stresses are linearly independent. Consequently, only one variable of the total 42 unknowns is linearly independent. 
Let us indicate with $\mathbf{A}_{e q} \mathbf{X}=\mathbf{b}_{e q}$ the system of equations obtained assembling all equality constraints, so that the unknown vector $\mathbf{X}$ has dimension $42 \times 1$, the coefficient matrix $\mathbf{A}_{e q}$ dimensions $41 \times 42$, and the vector of equalities constraints at the right hand side $\mathbf{b}_{e q}$ exhibits dimension $41 \times 1$. Let us assume as an independent variable the external load applied to the structure, i.e. $\lambda$, and let us assume that $\mathbf{X}(42,1)=\lambda$. With such assumptions, the equality constraints system may be written in a partitioned way as follows:

$$
\left[\begin{array}{l:l}
\tilde{\boldsymbol{A}}_{e q} & \tilde{\boldsymbol{A}}_{\lambda}
\end{array}\right]\left[\begin{array}{c}
\tilde{\boldsymbol{X}} \\
\hdashline \lambda
\end{array}\right]=\boldsymbol{b}_{e q}
$$

Here, $\widetilde{\mathbf{A}}_{e q}$ is a $41 \times 41$ matrix, $\widetilde{\mathbf{A}}_{\lambda}$ is a $41 \times 1$ vector whilst $\widetilde{\mathbf{X}}$ is the vector of global independent variables (dimension $41 \times 1$ ). From Equation (4), vector $\widetilde{\mathbf{X}}$ can be easily expressed as a function of loading multiplier $\lambda$, as follows $\tilde{\mathbf{X}}=\tilde{\mathbf{A}}_{e q}^{-1}\left[\mathbf{b}_{e q}-\tilde{\mathbf{A}}_{\lambda} \lambda\right]$. As a further step, assuming that linear inequality constraints are assembled into matrix $\tilde{\mathbf{A}}_{\text {in }}$, so that the assembled inequality constraints $\operatorname{read} \tilde{\mathbf{A}}_{\text {in }} \tilde{\mathbf{X}} \leq \mathbf{b}_{\text {in }}$, inequality constrains can finally be rewritten in a compact form as $\tilde{\mathbf{A}}_{i n} \tilde{\mathbf{A}}_{e q}^{-1}\left[\mathbf{b}_{e q}-\tilde{\mathbf{A}}_{\lambda} \lambda\right]-\mathbf{b}_{\text {in }} \leq \mathbf{0}$.

For the sake of simplicity, let assume that both bricks and mortar joints obey to MohrCoulomb failure criterion, the latter with a compression cut-off, see Figure 21. For the brick only two parameters are then required, namely the tensile and compressive strengths, whilst three parameters are necessary to specify the mortar response, in terms of cohesion, friction angle and compressive strength. For the static admissibility, the stress state of brick CST elements and of mortar interfaces must lie within the depicted strength domains. Whilst the stress domain for mortar is linear, the brick failure surface results to be nonlinear, but in view of a linear programming scheme it can be easily linearized using classic literature procedures, see for instance Milani [52].

In the framework of the lower bound theorem of classic limit analysis, it can be stated that the collapse load of the discretized mechanical system of Figure 20 may be found as: 


$$
F=\max \{\lambda\}
$$

subject to:

$$
\tilde{\mathbf{A}}_{i n} \tilde{\mathbf{A}}_{e q}^{-1}\left[\mathbf{b}_{e q}-\tilde{\mathbf{A}}_{\lambda} \lambda\right]-\mathbf{b}_{i n} \leq \mathbf{0}
$$

The linear programming problem given by Equations (5) is particularly appealing for its simplicity, because it is constituted exclusively by $n_{\text {in }}$ inequalities and a single optimization variable $\lambda$, without the presence of equality constraints. As schematized in Figure 21, size $n_{\text {in }}$ depends on the number of planes used to approximate the Mohr-Coulomb failure criterion for each brick element, say $n_{i n B}$. Then one has $n_{i n}=11 n_{i n B}+4 n_{i n M}$, where $n_{i n M}=3$ indicates the total number of straight lines used to define the mortar joint failure surface. It is noted that this linear programming problem may be solved by means of a standard spreadsheet, and its simplicity makes the approach adequate for design purposes. The solution to Eq. (7) is sought using a bisectional procedure, robust and straightforward, converging quickly to the desired solution.

In the framework of the lower bound theorem of limit analysis, the aforementioned procedure is repeated varying the finite element discretization of assigned prism geometry. In addition, also the curvature radius of the modeled prism can be perturbed, parametrized by means of lengths $\xi_{1}$ and $\xi_{2}$ represented in Figure 20, ranging from zero to the maximum allowable value, i.e. respectively $y_{6}$ and $y_{7}$. The maximum loading multiplier $\lambda$ among all possible values is assumed as the desired solution provided by the lower bound approach. Simultaneously, the lower bound limit analysis procedure provides the stress field over the interface, to be compared with the results of FE model predictions. In addition, the values of variable $\xi_{1}$ and $\xi_{2}$ corresponding to the maximum $\lambda$ suggest the shape of the failure mechanism, again to be compared with FE analyses.

The $\lambda$ function generated by the iterative solution of the mathematical programming problem in Eq. (5), with geometric parameters $\xi_{1}$ and $\xi_{2}$ ranging within the selected intervals, is drawn in Figure 22, with reference to a concave prism with constant curvature radius $\mathrm{R}_{0}$. The relevant distribution of principal stresses inside the bricks is depicted in Figure 23-a, whereas in Figure 23-b and $-\mathrm{c}$ the normal and shear stress at the FRP-masonry 
interfaces are shown. As it can be observed, a rather satisfactory agreement between standard "step-by-step" FEM and "direct" lower bound limit analysis is met, both for the collapse loading and the average stresses acting over the interface. Numerical simulations are repeated for all the curvatures previously inspected, finding the distribution of the collapse load reported in Figure 24, as a function of curvature radius. When comparing results of "direct" method with step-by-step FE model analysis, the maximum error on collapse loading amounts to about $15 \%$. Such uncertainty is rather satisfactory in view of the following considerations: (1) the limitations intrinsic to the assumptions of limit analysis model (perfect ductility and absence of softening); (2) the rough discretization used within the limit analysis approach (allowing for semi-manual calculations); (3) the fact that 3D effects are disregarded by a plane assumption.

The "direct" lower bound limit analysis strategy, above proposed mainly for a comparative assessment of "step-by-step" FE predictions, should be regarded indeed as a novel application in the field. It provides fast and reliable evaluations of the collapse load, taking into due consideration the presence of a curved reinforced surface. Moreover, it is expected to be easily used by practitioners with the help of a spreadsheet. The procedure may be improved by taking into account the uncertainty of mechanical properties and failure criteria for mortar and bricks.

\section{CLOSING REMARKS}

The aim of the present experimental and numerical investigation was to assess the bond behavior of FRP-reinforced curved masonry prisms, by correlating local phenomena (damage mechanisms, interface tractions at the GFRP strip-masonry joint) with the overall response (the reaction force versus the tangential slip). This study appears of paramount engineering interest when dealing with the strengthening or seismic retrofitting of masonry arches and vaults.

Firstly, an experimental campaign was carried out on masonry prisms with a curved reinforced surface, subjected to single-lap shear experiments. Both concave and convex geometries were tested. Detachment of the FRP from the masonry substrate involved thin layers of brick and mortar, as confirmed also by post-mortem inspection. 
The experimental data were interpreted by means of a heterogeneous three dimensional FE model. Model parameters were estimated on the basis of compressive tests on single constituents, when necessary integrated by literature suggestions. The FE model, once calibrated and validated, was used to predict the response of prisms with different curvature radii (not tested during the experimental campaign). By combining the experimental information with that provided by the mechanical model, it was possible to reconstruct the local stresses for different geometries, thus quantifying the effect of curvature on the interface response.

Finally, the predictions provided by the FE model were assessed through a comparison with a lower bound limit analysis approach, whose application to reinforced pillars is novel. A global agreement was met among all the sources of information herein considered (experiments, "step-by-step" damage model and "direct" limit analysis), which is encouraging and promising even for the engineering practice.

\section{ACKNOWLEDGMENTS}

Ismael Basilio would like to express his gratitude to the CONACYT for the scholarship granted during his $\mathrm{PhD}$, to the University of Minho for making possible the experimental campaign within its structural laboratory and the Danish Building Research during the FE models preparation.

\section{REFERENCES}

[1] CNR-DT-200 R1 (2012). Istruzioni per la Progettazione, l'Esecuzione ed il Controllo di Interventi di Consolidamento Statico mediante l'utilizzo di Compositi Fibrorinforzati. Consiglio Nazionale delle Ricerche, Rome, Italy.

[2] Lorezis L De, Miller B, Nanni A. Bond of fiber-reinforced polymer laminates to concrete. ACI Mat. J 2001;98(3):256-64.

[3] Yuan H, Teng JG, Seracino R, Wu ZS, Yao J. Full-range behavior of FRP-to-concrete bonded joints. Eng Struct 2004;26(5):553-64.

[4] Dai JG, Ueda T, Sato Y. Development of the nonlinear bond stress-slip model of fiber reinforced plastics sheet-concrete interfaces with a simple method. J Compos Cons ASCE 2005;9(1):52-62.

[5] Lu XZ, Ye LP, Teng JG, Jiang JJ. Meso-scale finite element model for FRP sheets/plates bonded to concrete. Eng Struct 2005;27(4):564-75.

[6] Chen JF, Teng JG. Anchorage strength models for FRP and steel plates bonded to concrete. J Struct Eng 2001;127(7):784-791.

[7] Yuan $\mathrm{H}, \mathrm{Wu} \mathrm{Z}$, Yoshizawa $\mathrm{H}$. Theoretical solutions on interfacial stress transfer of externally bonded steel/composite plates. J Struct Mech Earth Eng JSCE 2001;18(1):27-39. 
[8] Brosens K, Gemert VanD. Anchorage design for externally bonded carbon fiber reinforced polymer laminates. ACI SP 1999;188-56:635-641.

[9] Freddi F, Savoia M. Analysis of FRP-concrete debonding via boundary integral equations. Eng Frac Mech 2008;75:1666-1683.

[10] Ferracuti B, Savoia M, Mazzotti C. Interface law for FRP-concrete delamination. Compos Struc 2007;80:523-531.

[11] Lu XZ, Teng JG, Ye LP, Jiang JJ. Bond-slip models for FRP sheets/plates bonded to concrete. Eng Struc 2005;27:920-937.

[12] Chen JF, Pan WK. Three dimensional stress distribution in FRP-to-concrete bond test specimens Cons Build Mat 2006;20:46-58.

[13] Coronado CA, Lopez M. Damage approach for the prediction of debonding failure on concrete elements strengthened with FRP. J Compos Constr ASCE 2007;11(4):391-400.

[14] Biscaia HC, Chastre C, Silva MAG. Nonlinear numerical analysis of the debonding failure process of FRP-to-concrete interfaces. Compos Part B Eng 2013;50:210-223.

[15] Biscaia HC, Chastre C, Silva MAG. Modelling GFRP-to-concrete joints with interface finite elements with rupture based on the Mohr-Coulomb criterion. Const Build Mat 2013;47:261-273.

[16] Subramaniam KV, Focacci F, Carloni C. An investigation on the interface fracture propagation between FRP and masonry. In Proc.: MuRiCo 3, mechanics of masonry structures strengthened with composite materials: modeling, testing, design, control. Venice, Italy April 2009.

[17] Aiello MA, Sciolti SM. Bond analysis of masonry structures strengthened with CFRP sheets. Cons Build Mat 2006;20:90-100.

[18] Basilio I, Oliveira D, Lourenço PB. Experimental characterization of frp- masonry interface behavior. In: Proc.: 5th International Conference AMCM 2005 Gliwice - Ustron', Poland; 2005

[19] Fagone M, Briccoli Bati S. Analisi e caratterizzazione meccanica della modalità di rottura di rinforzi in CFRP su elementi in laterizio. In: Proc.: GIMC 2008 Alghero, Sept Italy 2008.

[20] Capozucca R. Experimental FRP/SRP-historic masonry delamination. Compos. Struct 2010; 92:891-903.

[21] Fedele R, Milani G. Assessment of bonding stresses between FRP sheets and masonry prisms during delamination tests. Comp Part B 2012;43:1999-2011.

[22] Fedele R, Milani G. Three-dimensional effects induced by FRP-from-masonry delamination. Compos Struct 2011;93(7):1819-31.

[23] Biolzi L, Ghittoni C, Fedele R, Rosati G. Experimental and Theoretical Issues in FRP-Concrete Bonding. Const Build Mat 2013;41:182-190.

[24] Luccioni B, Rougier VC. Shear behavior of brick-mortar interface in CFRP retrofitted or repaired masonry. Int J Mech Sci 2010;52:602-11.

[25] Aiello MA, Sciolti MS, Triantafillou TC. FRP- strengthened masonry: Bond aspects. FRPRCS-8 (CD-ROM) Univ of Patras. Patras, Greece 2007.

[26] Grande E, Imbimbo M, Sacco E. FRP-strengthening of masonry structures: Effect of debonding phenomenon. In: Proc.: VI Int Conf Struc Anal Hist Cons. Taylor and Francis London 2008:10171023.

[27] Basilio I. Strengthening of arched masonry structures with composite materials. $\mathrm{PhD}$ thesis, University of Minho, Department of Civil Engineering, Portugal October 2007, available at: http://www.civil.uminho.pt/masonry/Publications/Update_Webpage/2007_PhD_IsmaelBasilio.pdf.

[28] Oliveira D, Basilio I, Lourenço PB. Experimental bond behavior of FRP sheets glued on brick masonry. ASCE J. Compos Cons 2011;15(1):32-41.

[29] Lourenco PB, Almeida JC, Barros JA. Experimental investigation of bricks under uniaxial tensile testing. J British Masonry. Society Masonry Int 2005;18(1).

[30] Lourenco PB, Martins JP. Strengthening of the architectural heritage with composite materials. In: Proc.: Compos Cons. Figueiras et al. (eds) Swets and Zeitlinger 2001:571-576. 
[31] Valluzzi MR, Valdemarca M, Modena C. Behavior of brick masonry vaults strengthened by FRP laminates. ASCE J Compos for Cons 2001;5(5):163-169.

[32] Cancelliere I, Imbimbo M, Sacco E. Experimental tests and numerical modeling of reinforced masonry arches. Eng Struc 2010;32(3):776-792.

[33] Grande E, Imbimbo M, Sacco E. Bond behavior of CFRP laminates glued on clay bricks: experimental and numerical study. Compos Part B Eng 2011;42(2):330-40.

[34] Valluzzi MR, Oliveira DV, Caratelli A, Castori G, Corradi M, de Felice G, et al. Round Robin Test For Composite-To-Brick Shear Bond Characterization. Mat and Struct - RILEM. 2012;45(12):17611791.

[35] Panizza M, Garbin E, Valluzzi MR, Modena C. Bond behavior of CFRP and GFRP laminates on brick masonry. In: Proc.: VI Int Conf on Struc Anal of Hist Cons. Bath (UK) July 2-4. D'Ayala \& Fodde eds 2008:763-770.

[36] Oliveira D, Basilio I, Lourenço P.B. Experimental bond behavior of FRP sheets glued on brick masonry. J Compos Cons ASCE 2011;15(1):32-41.

[37] Grande E, Imbimbo M, Sacco E. Simple Model for the Bond Behavior of Masonry Elements Strengthened with FRP. J Compos Cons 2011;15(3):354-363.

[38] Ghiassi B, Marcari G, Oliveira DV, Lourenço PB. Numerical analysis of bond behavior between masonry bricks and composite materials. Eng Struct 2012;43:210-220.

[39] Malena M, de Felice G. Externally bonded composites on a curved masonry substrate: experimental results and analytical formulation. Submitted for publication to Compos Struc 2013.

[40] Failla A, Cottone A, Gianbanco G. Numerical modeling of masonry structures reinforced by FRP plate/sheets. In: Lourenço, Roca editors. Struc Anal Hist Cons - Modena. London Taylor and Francis Group 2005:857-66.

[41] Fernandes F, Lourenco PB. Evaluation of the compressive strength of ancient clay bricks using microdrilling. J. Mat Civ Eng ASCE. 2007;19(9):791-800.

[42] Binda L, Tiraboschi C, Mirabella Roberti G, Baronio G, Cardani G. Measuring masonry material properties: detailed results from an extensive experimental research. Part I: Tests on masonry components. Report 5.1 CD-ROM 1-263 April 1996a.

[43] Binda L, Tiraboschi C, Mirabella Roberti G, Baronio G, Cardani G, Measuring masonry material properties: detailed results from an extensive experimental research. Part II: Tests on masonry specimens. Report 5.1 CD-ROM 1-210 October 1996.

[44] ASCE 5-95TMS 402-95 (1989). Building Code Requirements for Masonry Structures. American Concrete Institute: ASCE 5-95TMS 402-95.

[45] Comi C, Perego U. Fracture energy based bi-dissipative damage model for concrete. Int J Solids Struc 2001;38:6427-6454.

[46] Comi C, Fedele R, Perego U. A chemo-thermo-damage model for the analysis of concrete dams affected by alkali-silica reaction. Mech Mat 2009;41:210-230.

[47] Fedele R, Scaioni M, Barazzetti L, Rosati G, Biolzi L. Delamination tests on CFRP-reinforced masonry prisms: optical monitoring and mechanical modeling. Cement Concrete Composites 2013 doi:10.1016/j.cemconcomp.2013.10.006.

[48] Abaqus. Release 6.9. Theory and User's manuals. Dassault Systèmes, Simulia Corp., Providence RI, US, 2009.

[49] Sejnoha M, Zeman J. Micromechanics in Practice, WIT Press, Southampton, Boston, 2013.

[50] Dvorak GJ, Sejnoha M. Initial failure maps for fibrous SMC laminates, Journal of the American Ceramic Society 1995; 78: 205-210.

[51] Dvorak JG, Sejnoha M. Initial failure maps for ceramic and metal matrix composites, Modelling Simul. Mater. Sci. Eng. 1996; 4: 553-580.

[52] Milani G. 3D upper bound limit analysis of multi-leaf masonry walls, International Journal of Mechanical Sciences 2008; 50(4): 817-836. 
[53] Sloan SW. Lower bound limit analysis using finite elements and linear programming. Int J Numer Anal Meth Geomech 1988;12:61-77.

[54] Anderheggen E, Knopfel H. Finite element limit analysis using linear programming. International Journal of Solids and Structures 1972;8:1413-31.

[55] Poulsen PN, Damkilde L. Limit state analysis of reinforced concrete plates subjected to in-plane forces. Int J Solids Struct 2000;37: 6011-29.

[56] Milani G, Lourenço PB, Tralli A. Homogenised limit analysis of masonry walls, Part II: Structural examples 2006; 84: 181-195. 


\section{[57] FIGURES}
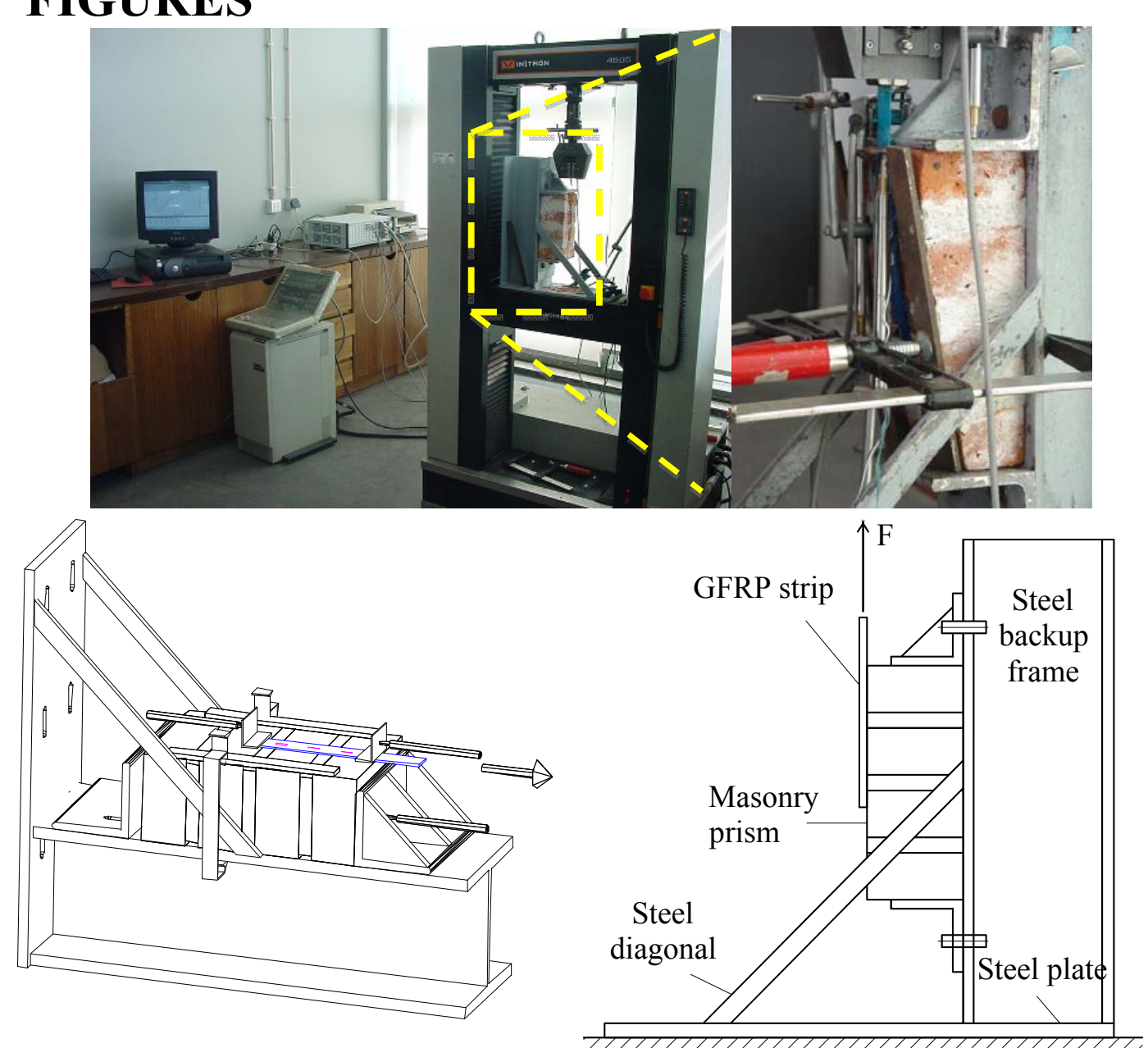

a)

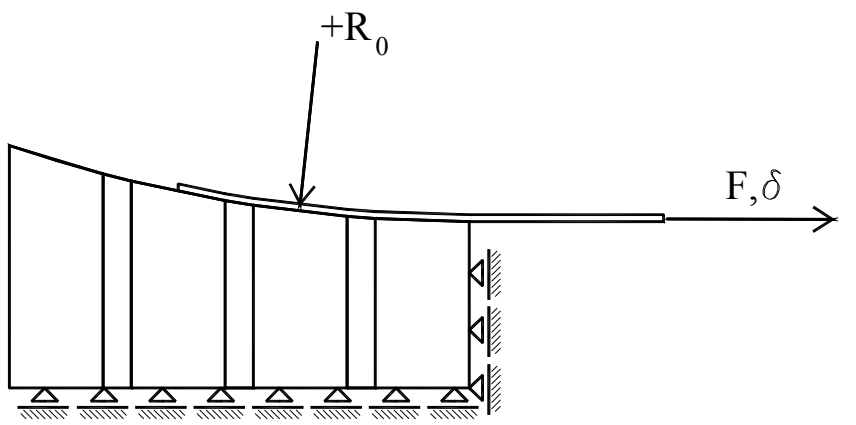
$+\mathrm{R}_{0}$ configuration convex case

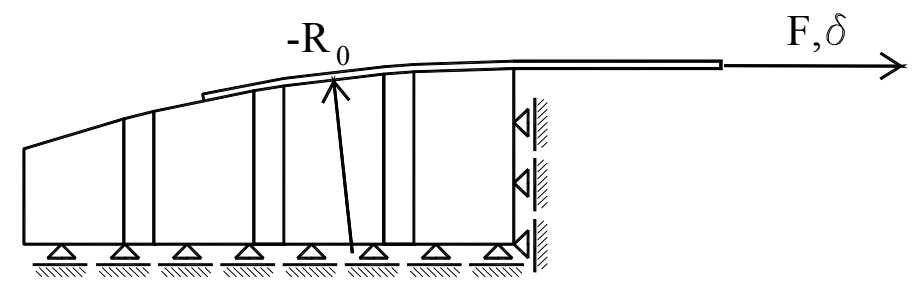

$-\mathrm{R}_{0}$ configuration convex case

Figure 1: Experimental set-up for single lap shear tests, in a) and b), and geometry of masonry prisms tested in the experimental campaign, with boundary conditions in c). 


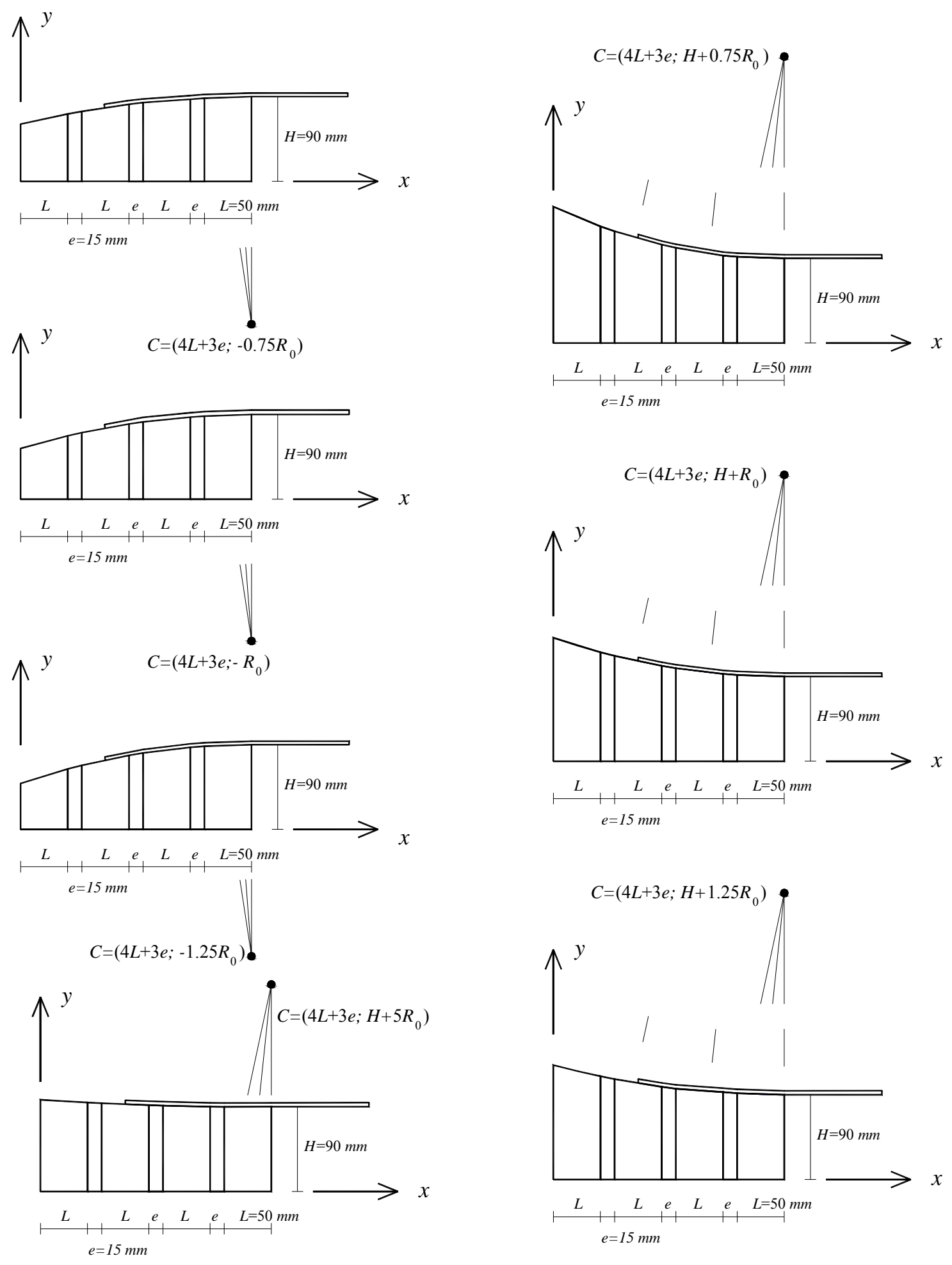

Figure 2: Geometry and sizes of masonry prisms with different curvature radii, considered for the numerical simulations. 


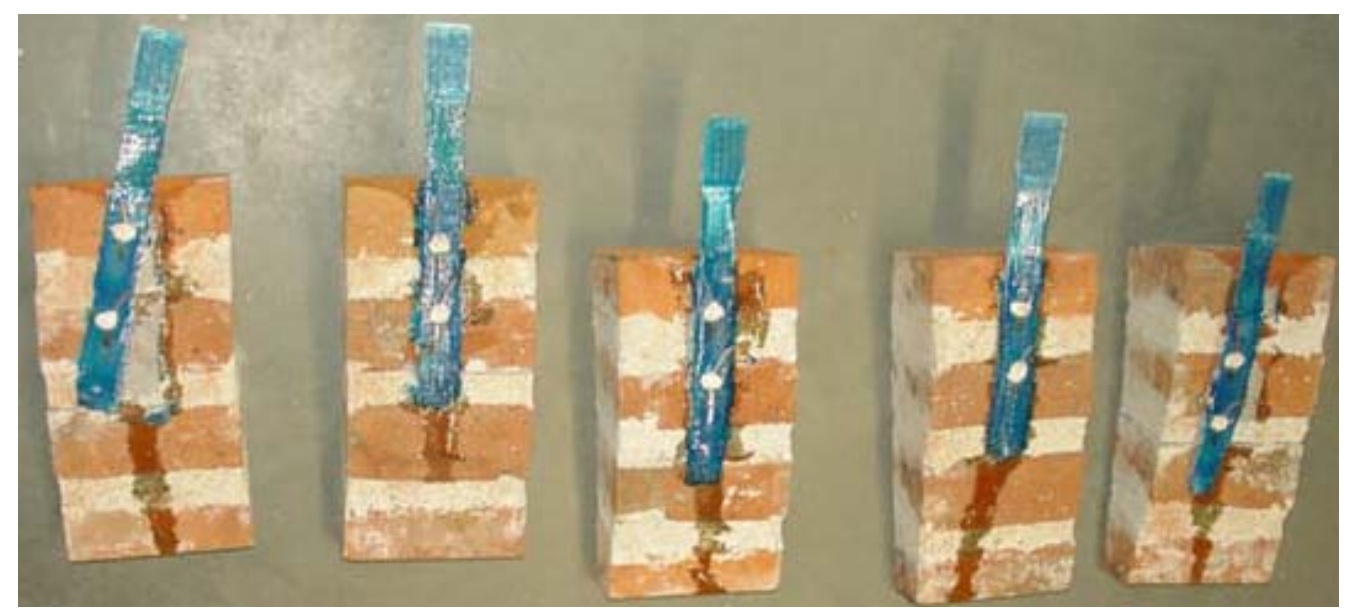

a)

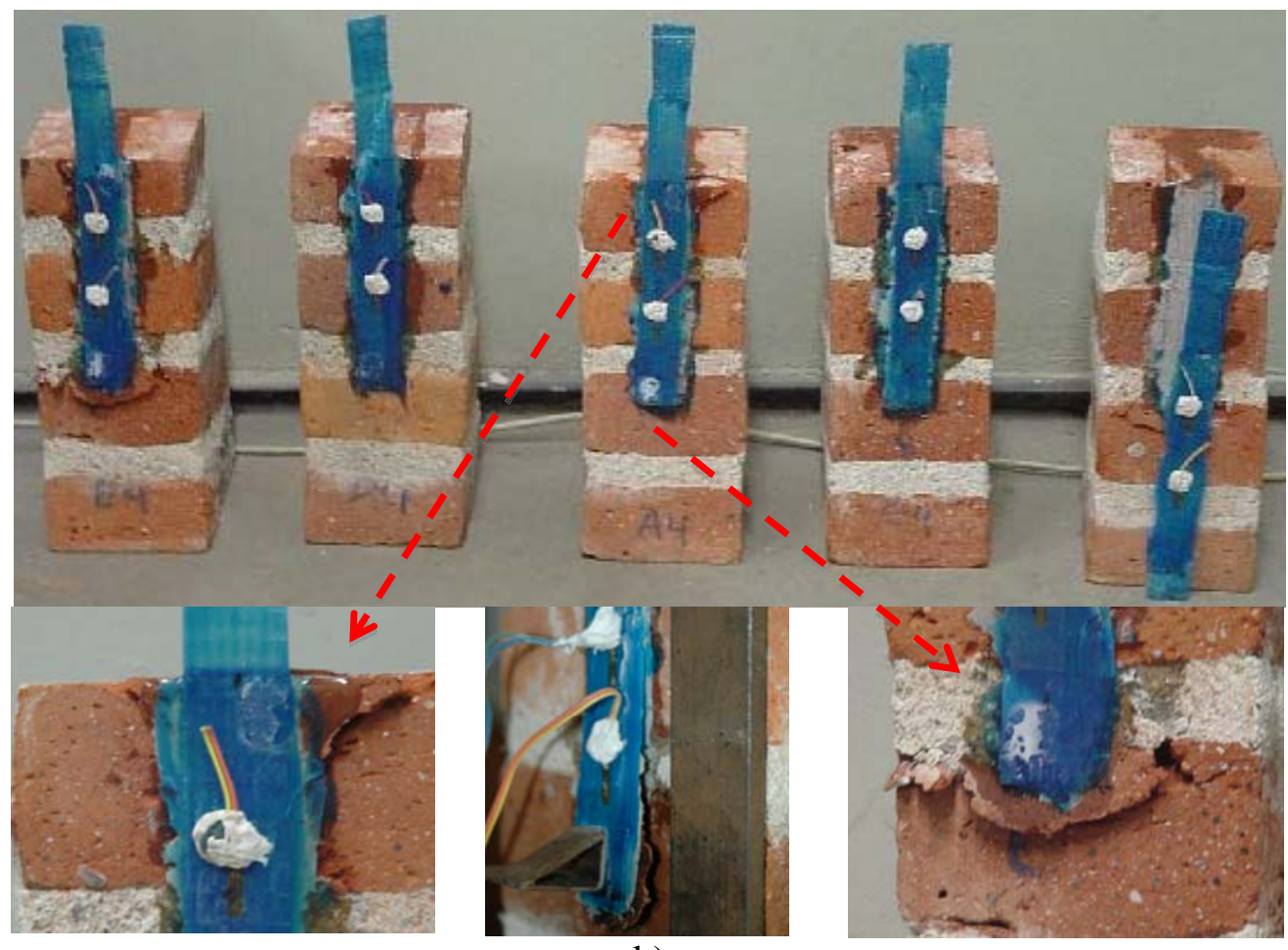

b)

Figure 3: Post-mortem picture of masonry prisms, with a concave in a) and a convex profile in $b$ ). A thick layer of the masonry prism remains attached to the detached reinforcement [27]. 


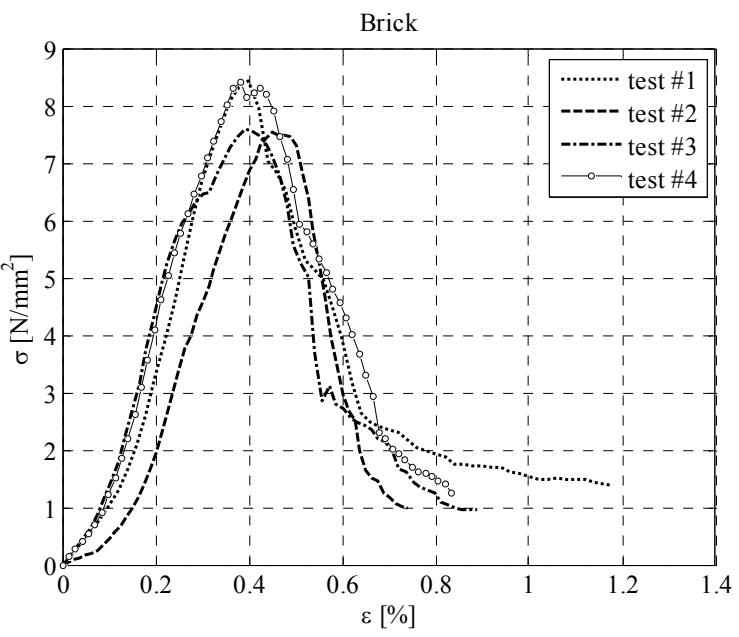

a)

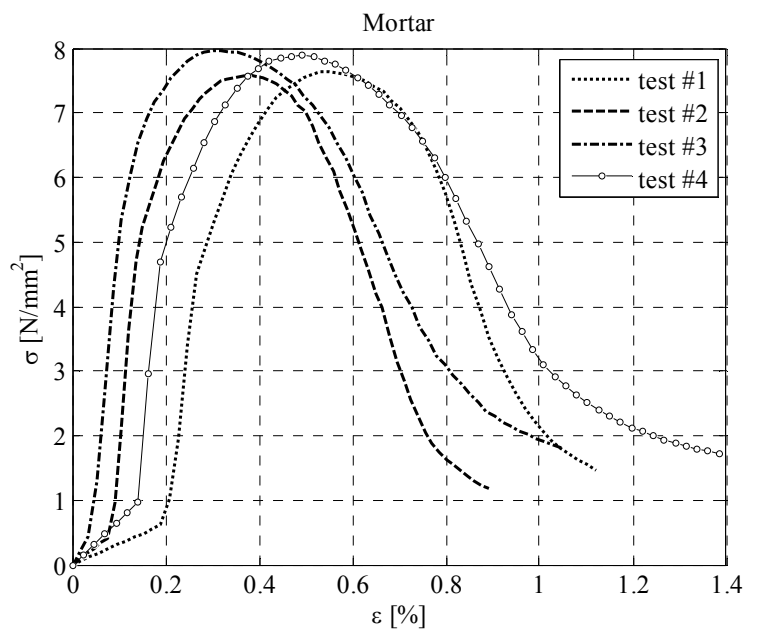

b)

Figure 4: Experimental response stress-strain curves obtained in compression for blocks (a), brick and (b) mortar. 


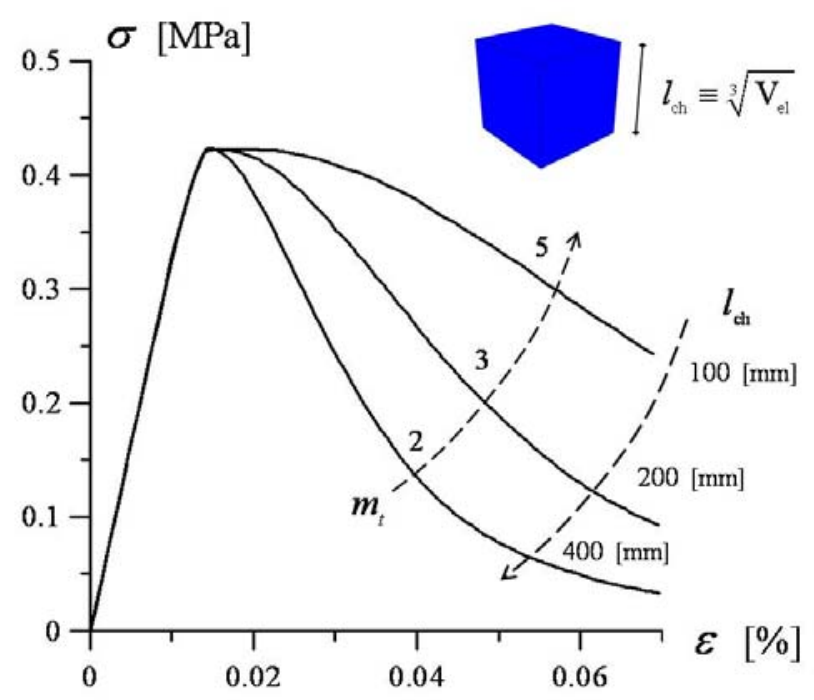

Figure 5: Fracture energy regularization based on the characteristic length $l_{\text {eq }}$ at varying the finite element size. When increasing the equivalent characteristic length $l_{\mathrm{ch}}$, parameter $\mathrm{m}_{i}$ $(i=t, c)$ decreases, and vice versa. Herein reference is made to a uniaxial test in tension on brick material. 
a)
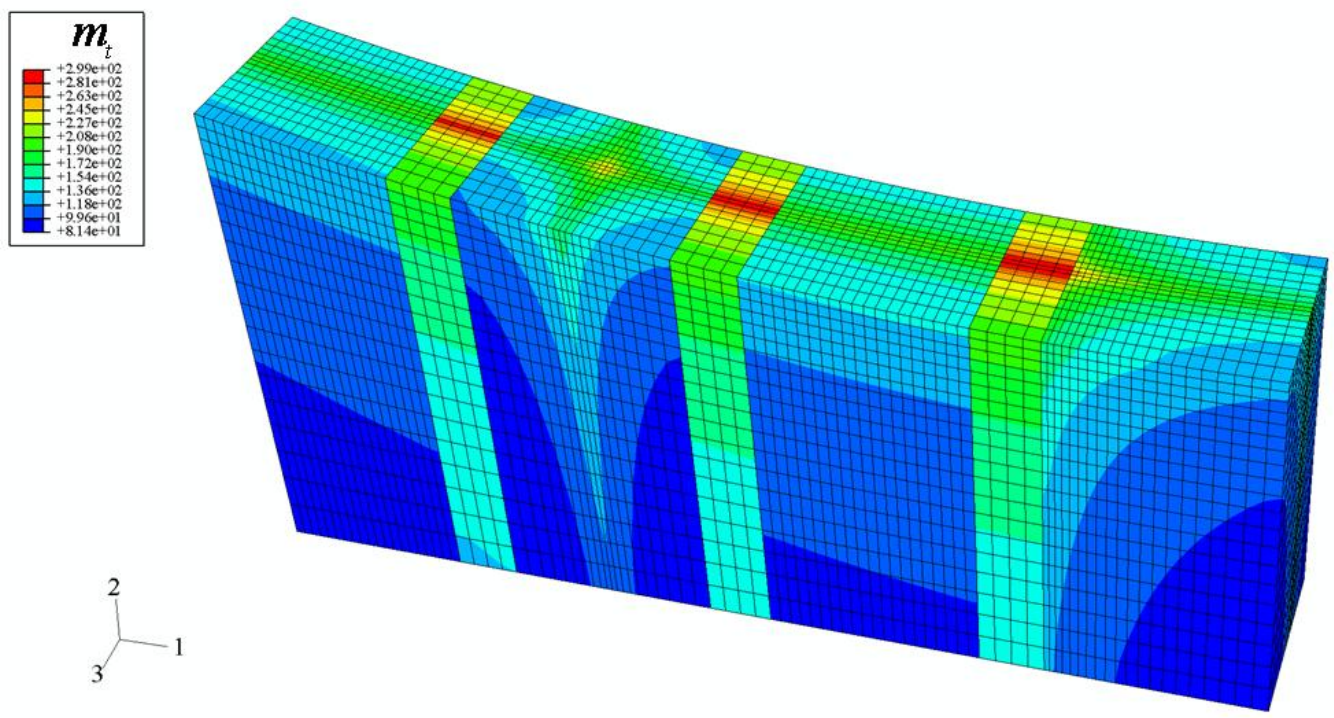

b)
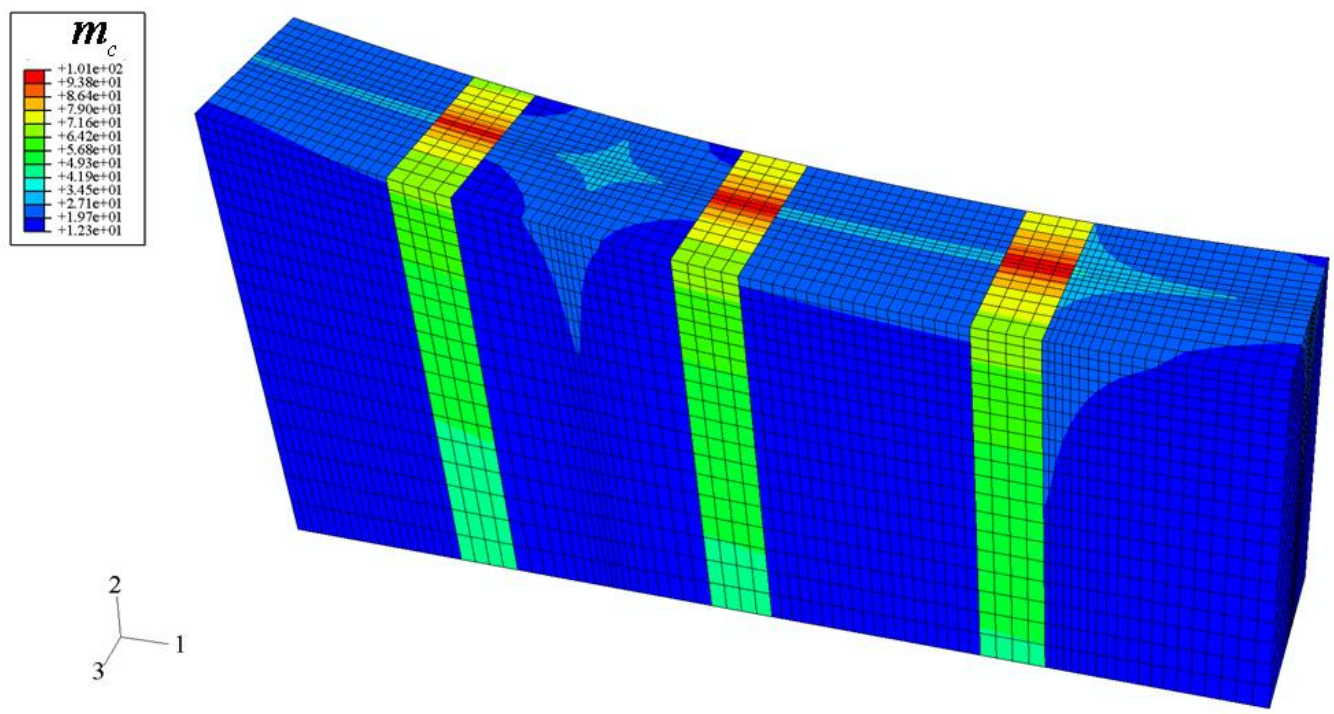

Figure 6: Finite element discretization of a curved masonry prism. Distribution of parameters $\mathrm{m}_{t}$ and $\mathrm{m}_{c}$ in a) and b), governing the post-peak branches of the softening functions $h_{t}$ and $h_{c}$, in tension and compression respectively, estimated by the present fracture energy regularization strategy separately for brick and mortar. 


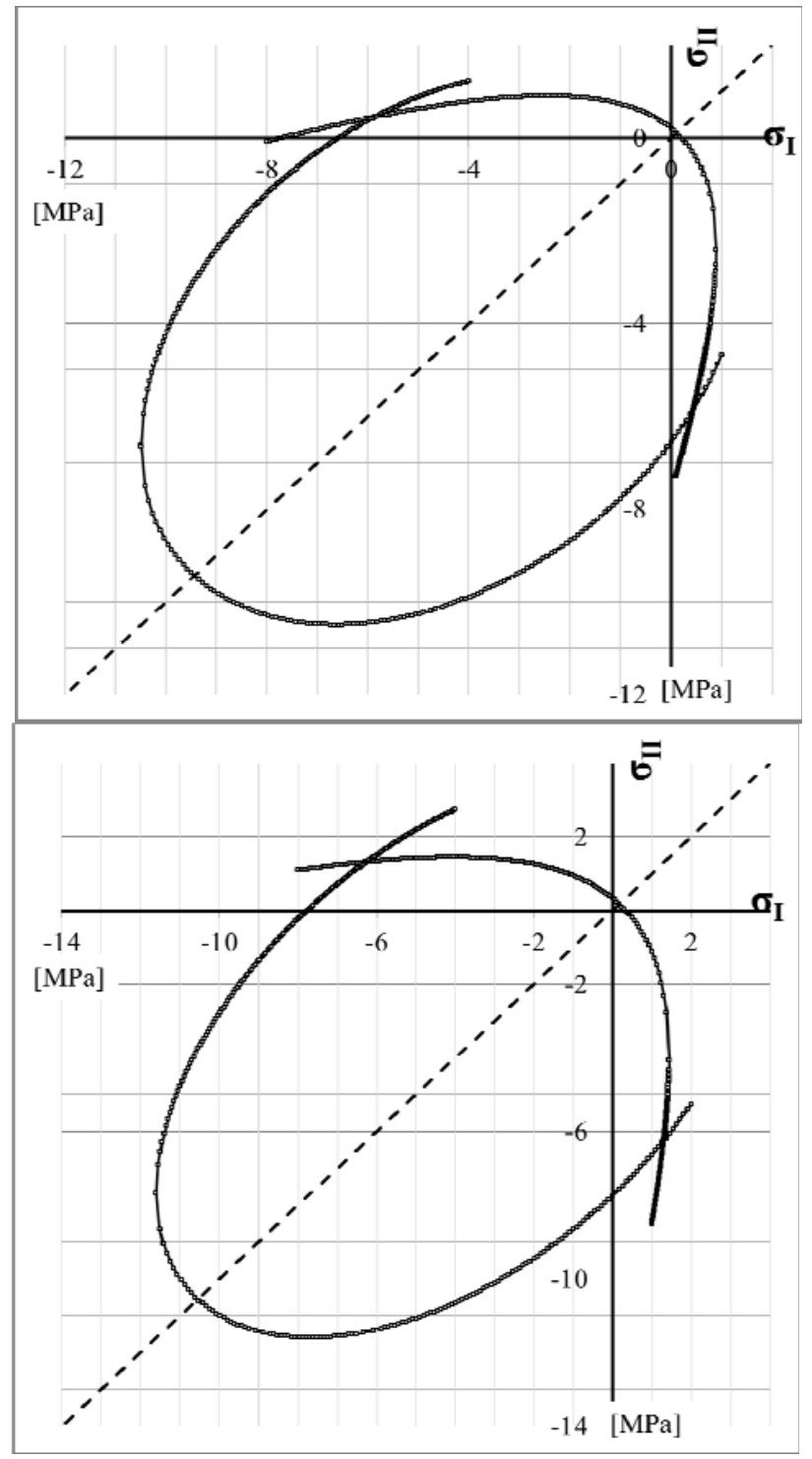

a)

b)

Figure 7: Initial elastic domain under plane stress conditions, in the Haar Westergaard plane: a) mortar failure domain; b) brick failure domain. 


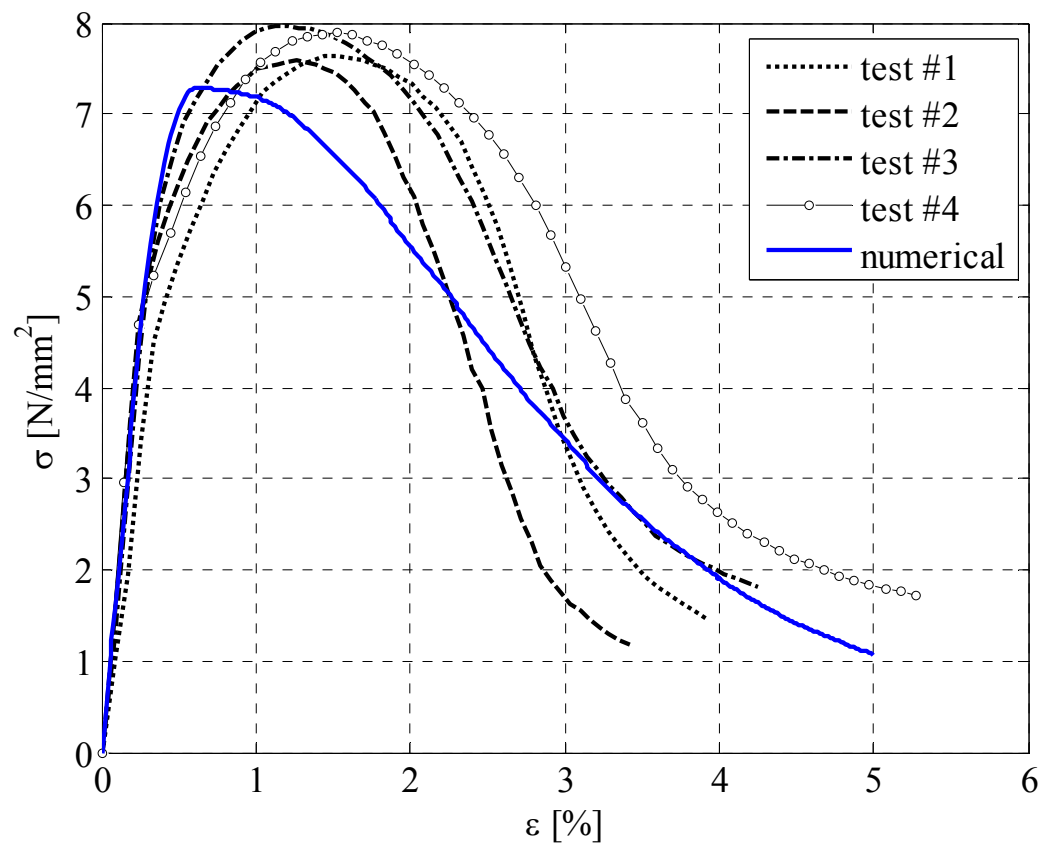

a)

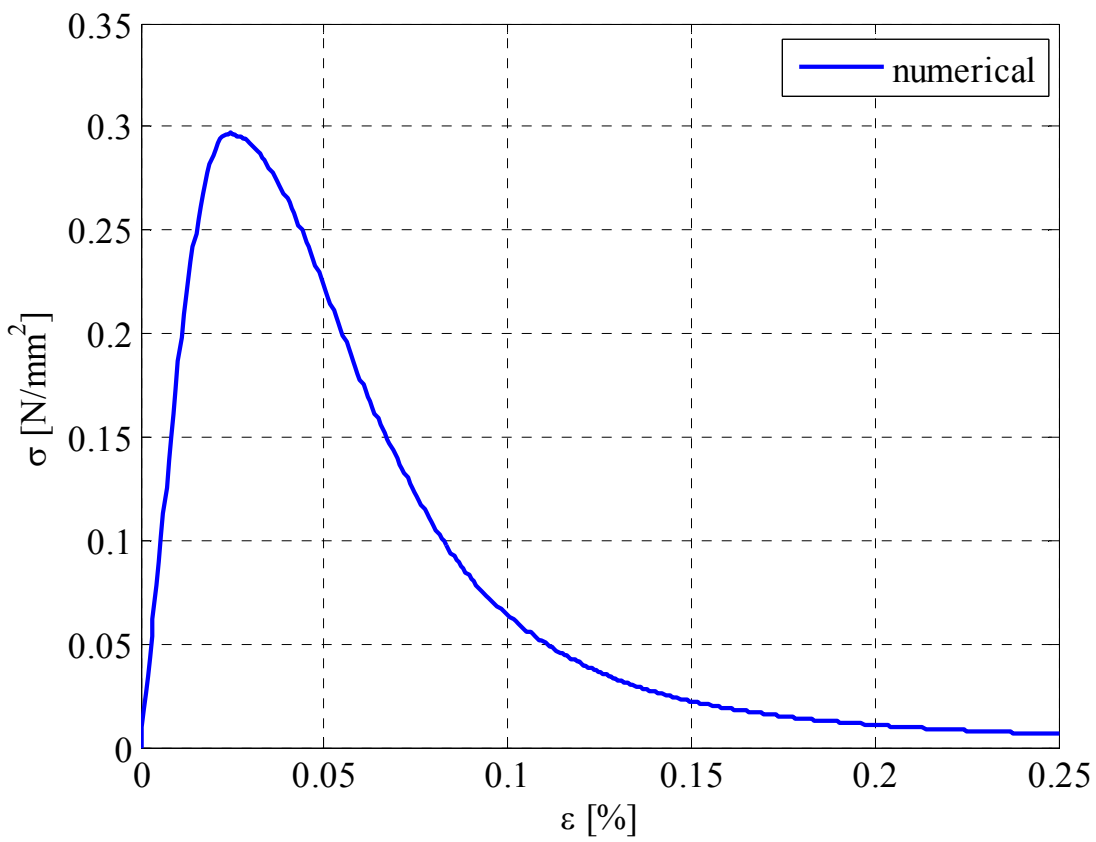

b)

Figure 8: Mortar uniaxial behavior adopted for the numerical simulations: a) compression response, in comparison with experimental data; b) tensile response. 


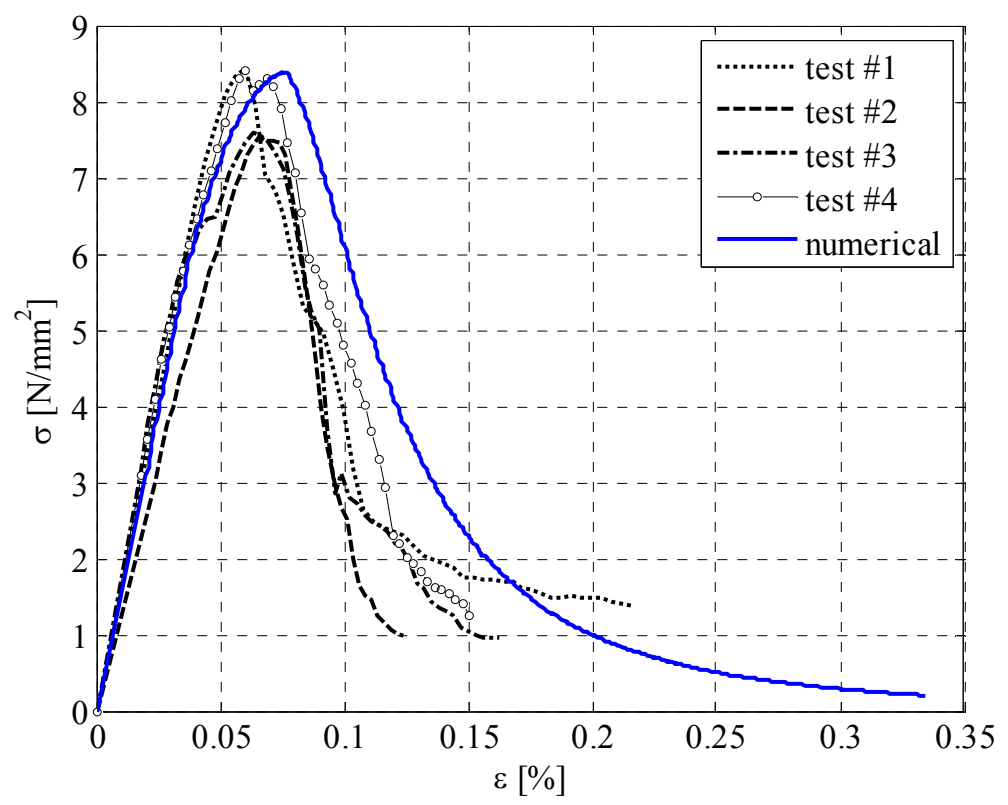

a)

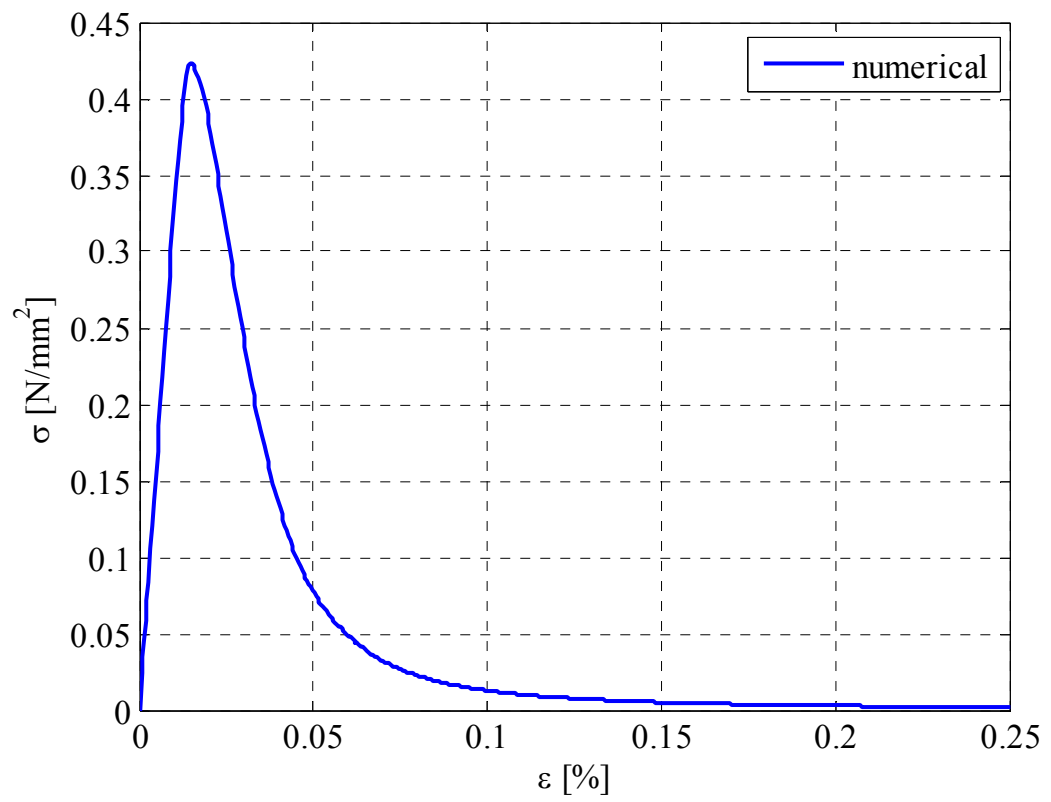

b)

Figure 9: Brick uniaxial behavior adopted for the numerical simulations: a) compression response, in comparison with experimental data; b) tensile response. 

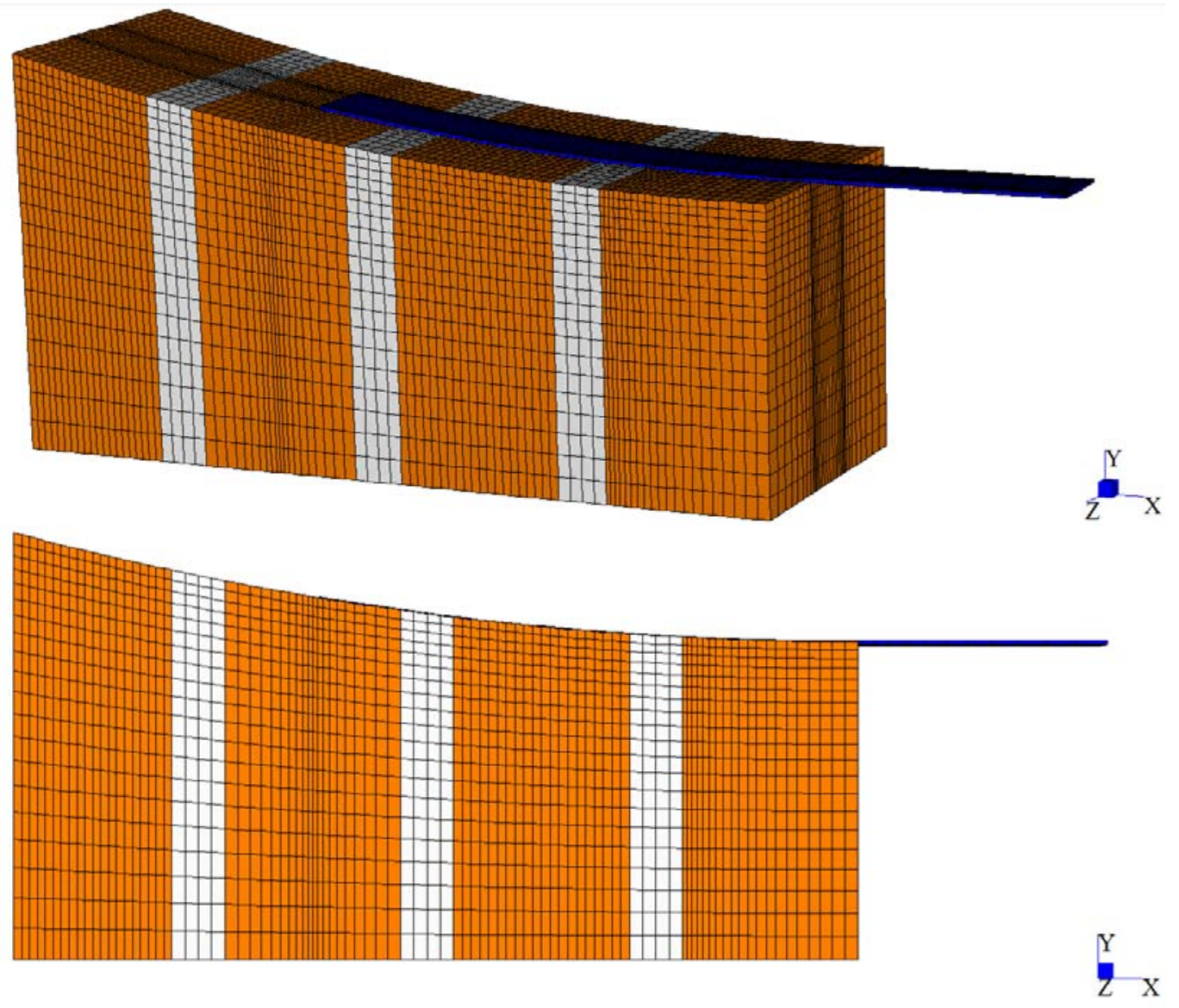

Figure 10: FE discretization of the reinforced prisms, constituted of 60,000 "brick" eight-noded elements. 


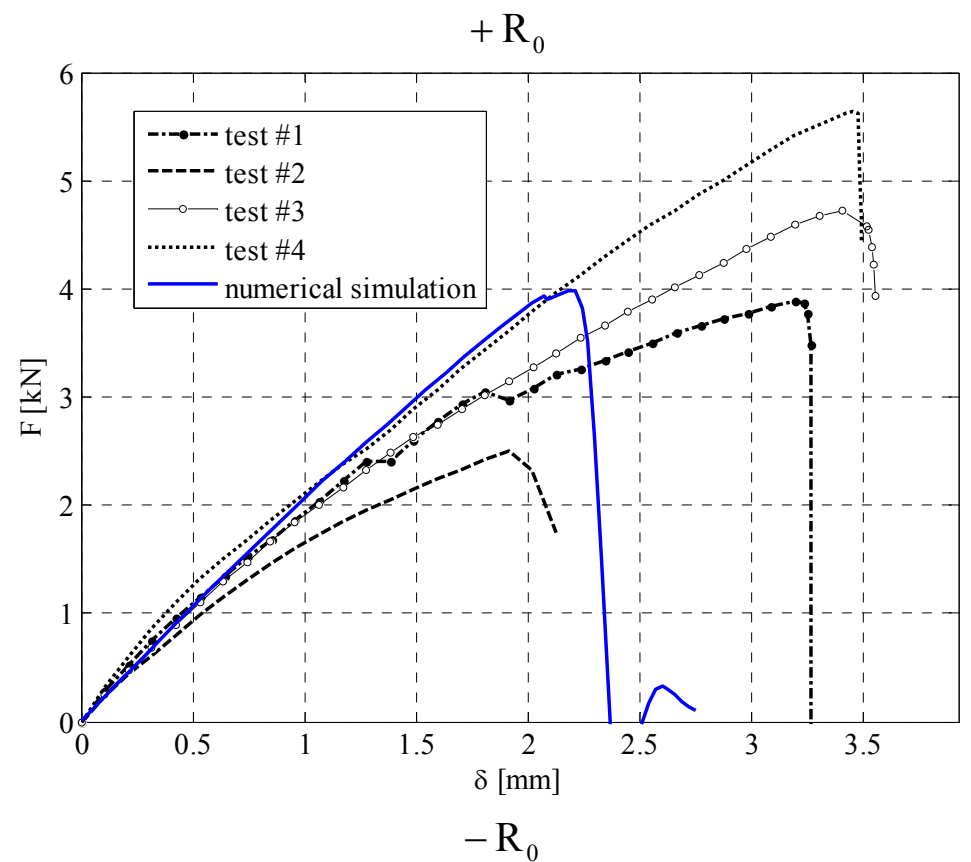

a)

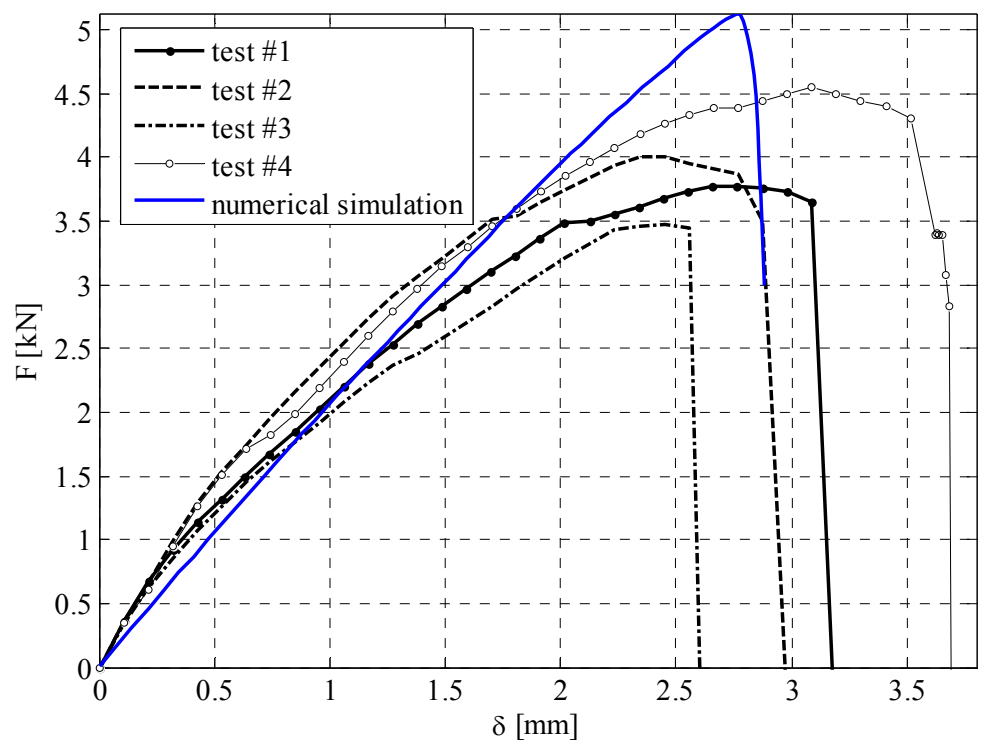

b)

Figure 11: Overall response under single-lap shear tests, in terms of reaction force versus prescribed displacement, and their computed counterparts, of: a) convex and b) concave reinforced prisms. 


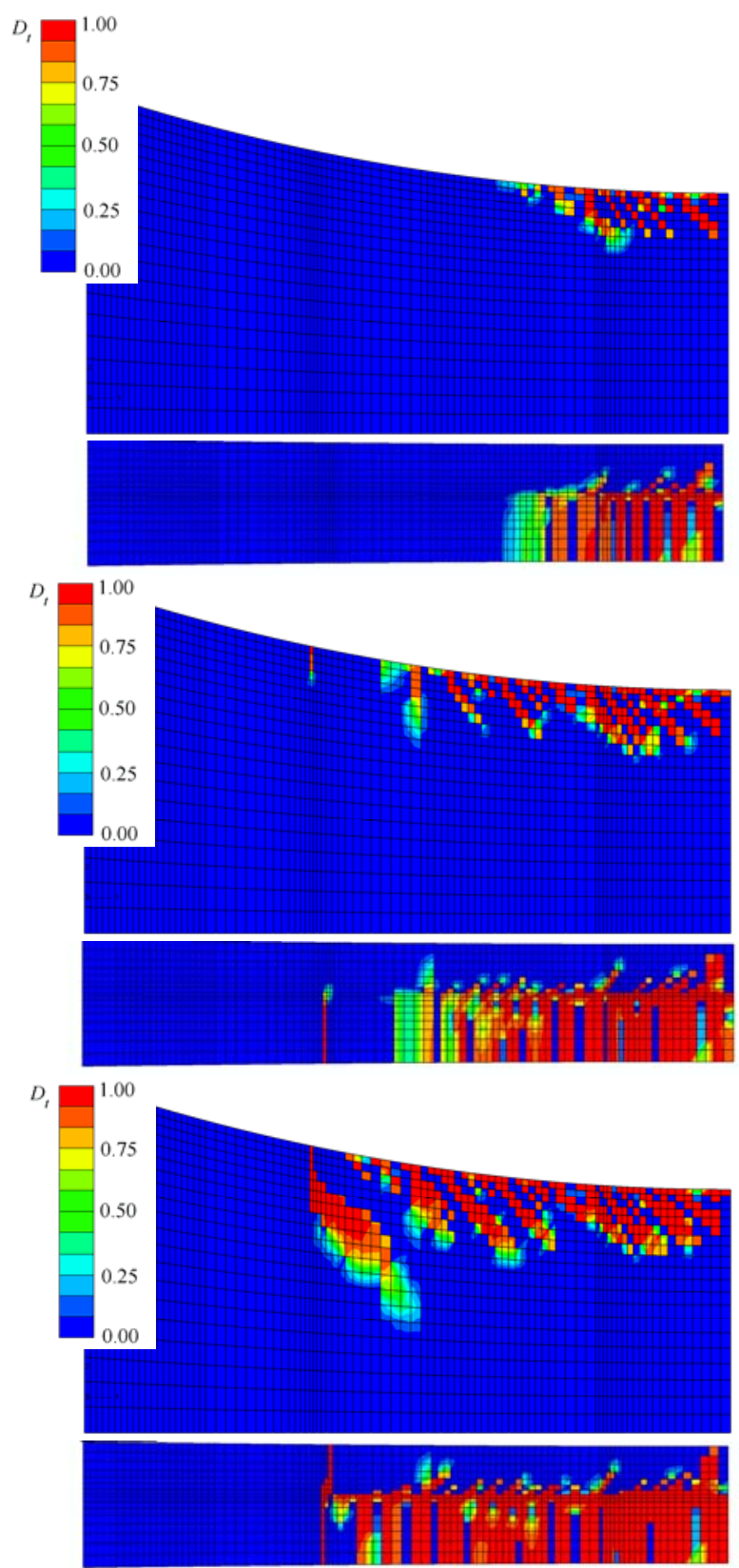

a)

b)

c)

Figure 12: Damage evolution on convex specimen predicted by the FE model at different instants during the test simulation, at $1 / 3$ (a), $2 / 3$ (b) $3 / 3$ (c) times the peak loading. 


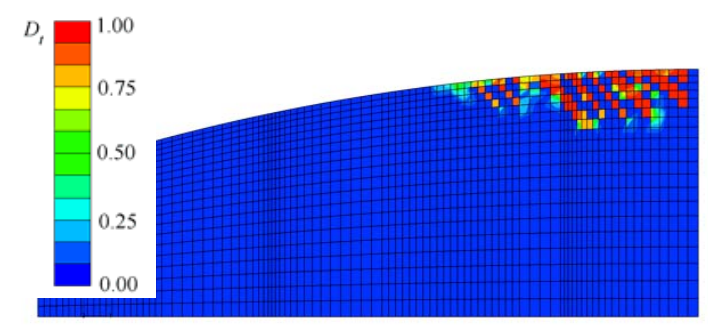

a)
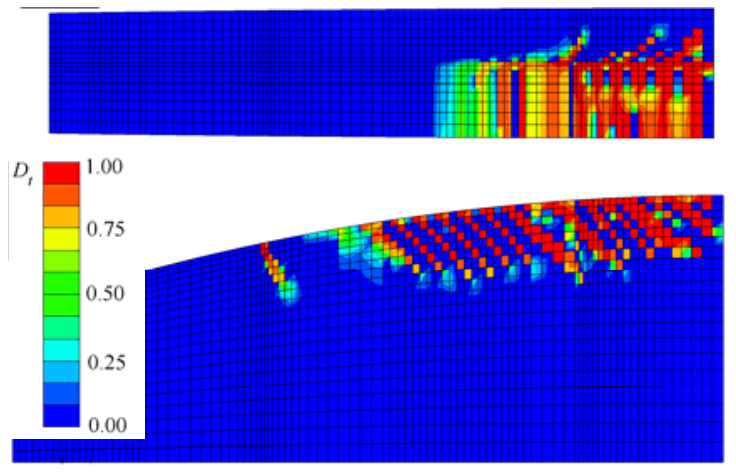

b)
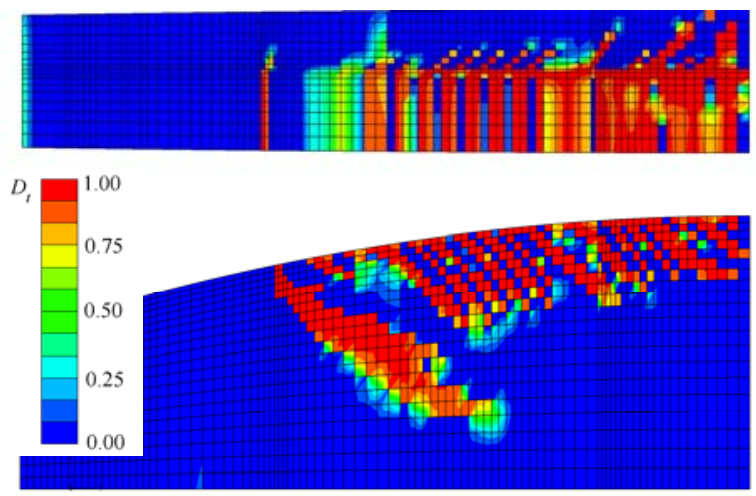

c)

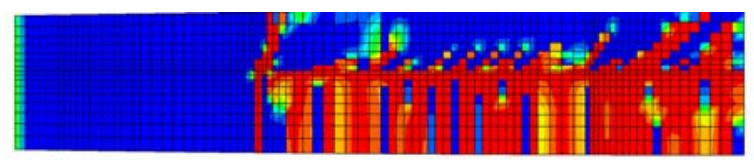

Figure 13: Damage evolution on concave specimen predicted by the FE model at different instants during the test simulation, at $1 / 3$ (a), 2/3 (b) 3/3 (c) times the peak loading. 


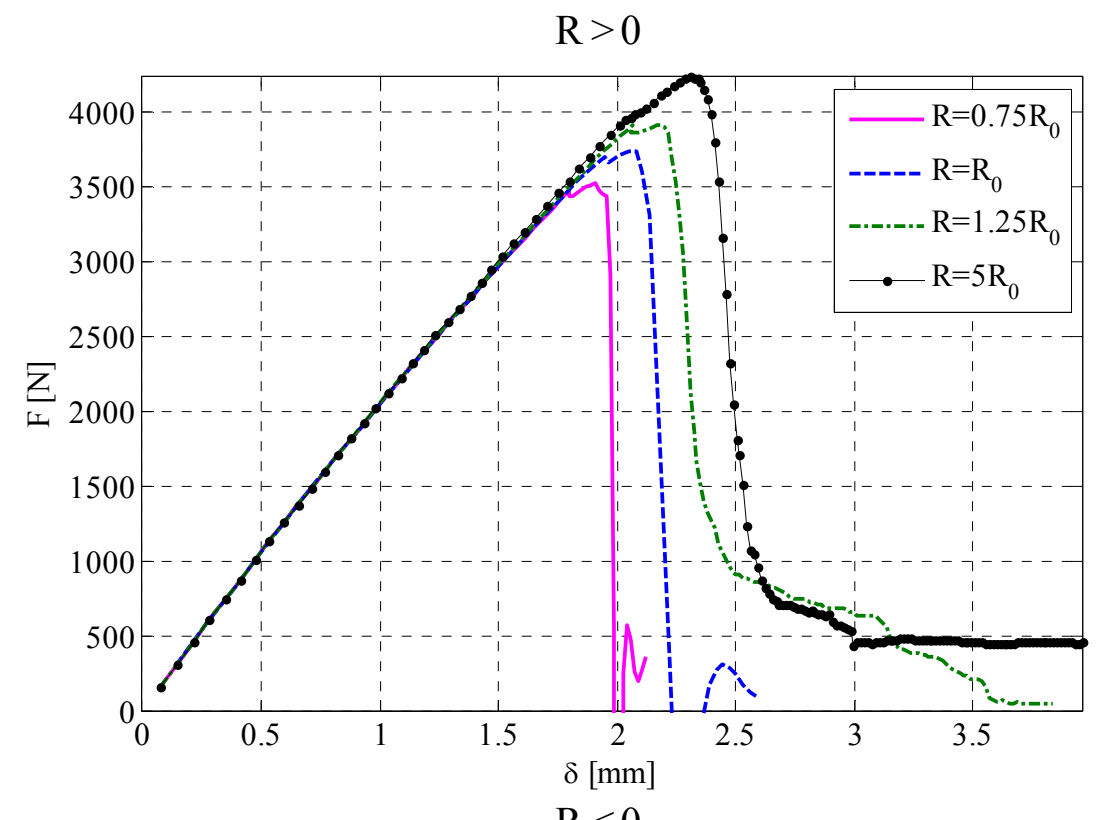

a)

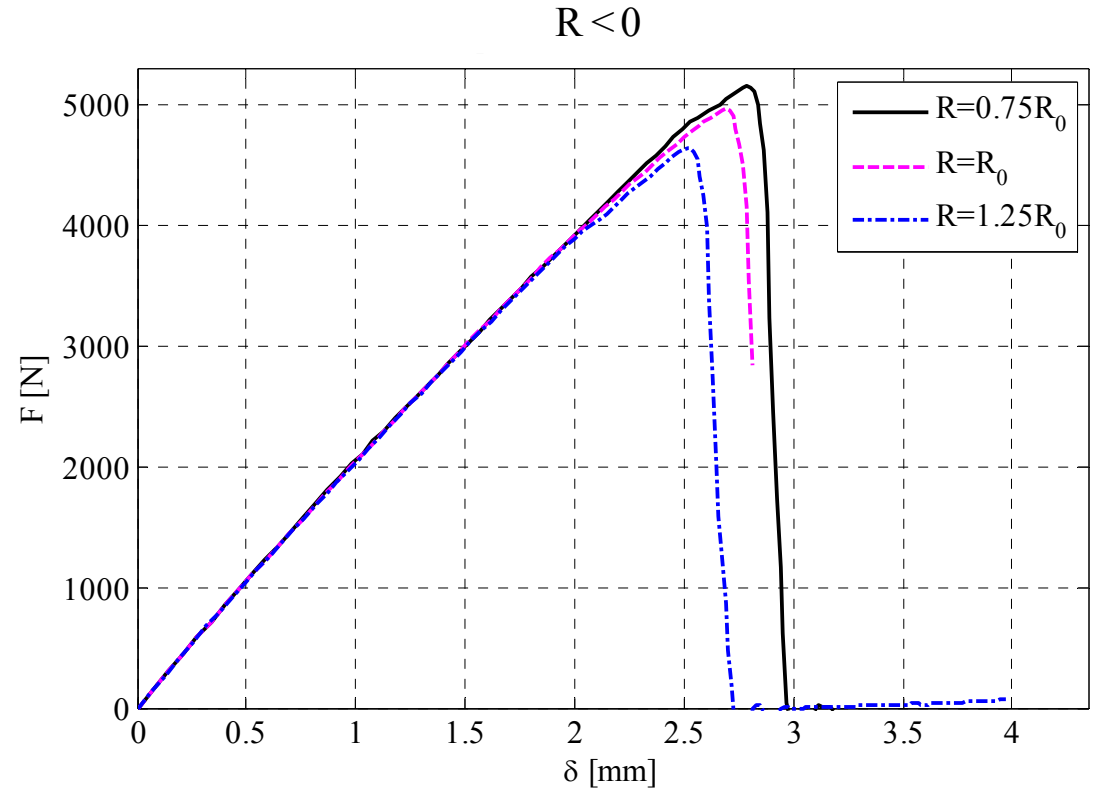

b)

Figure 14: Overall response under single-lap shear tests, in terms of reaction force versus tangential slip, computed by the FE model at varying the curvature radius: a) convex and b) concave reinforced samples. 


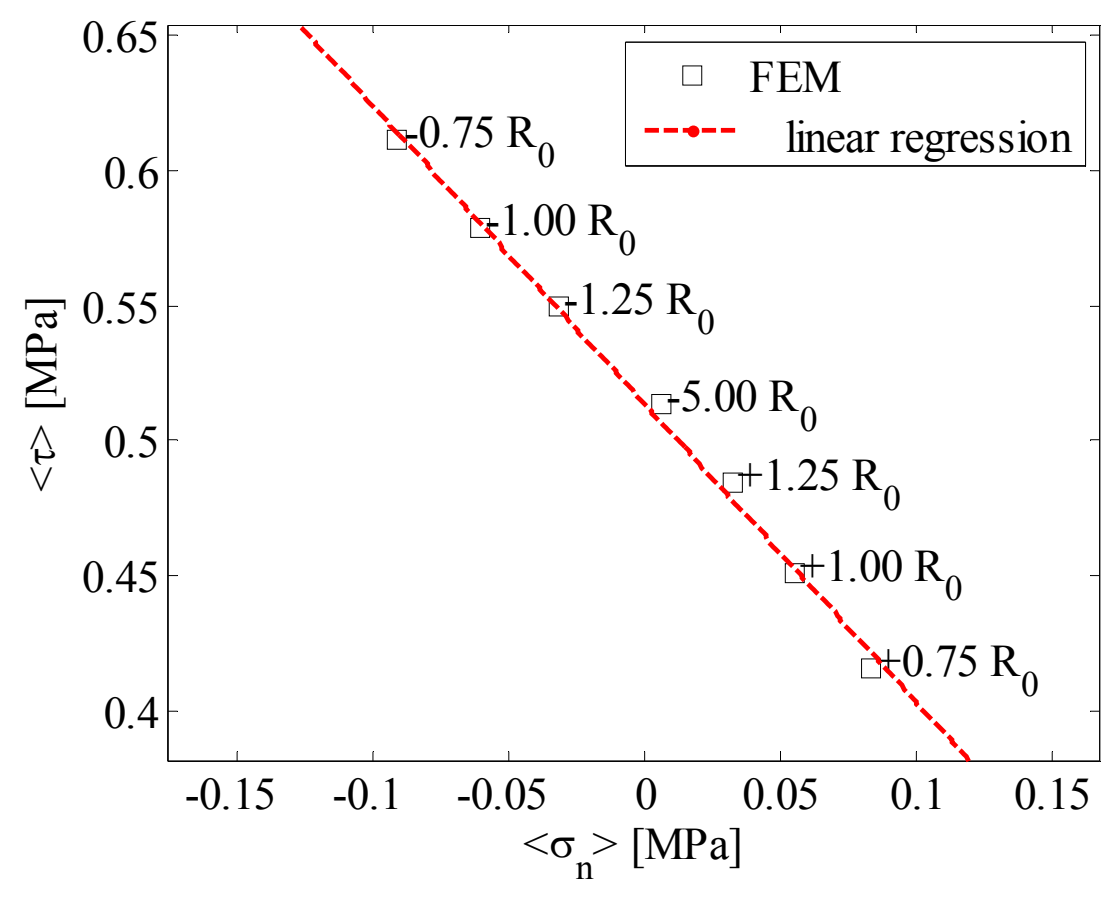

Figure 15: Mohr plane representation: average normal and shear stresses acting over the FRP-masonry interface, at different curvature radii. 


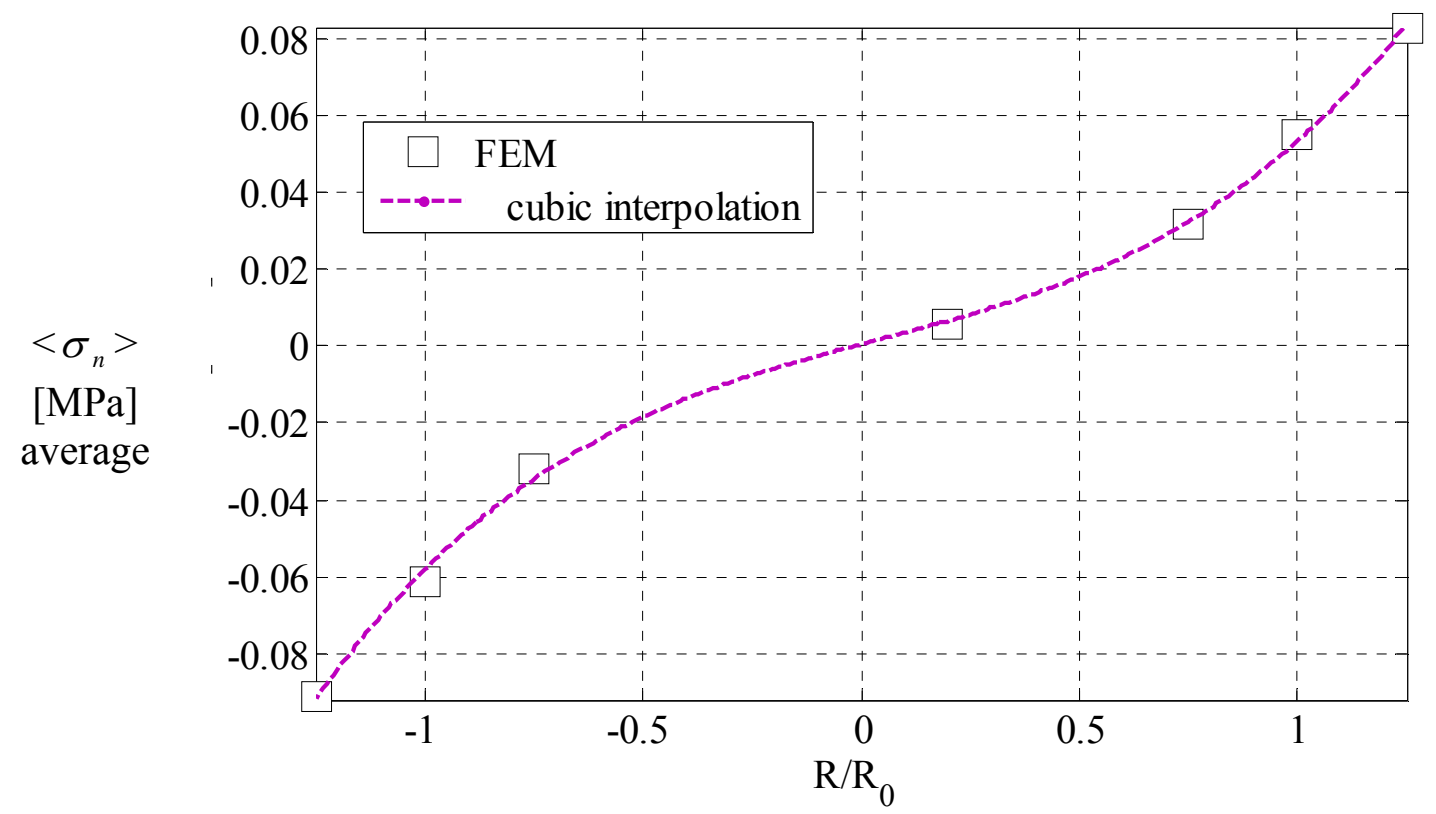

a)

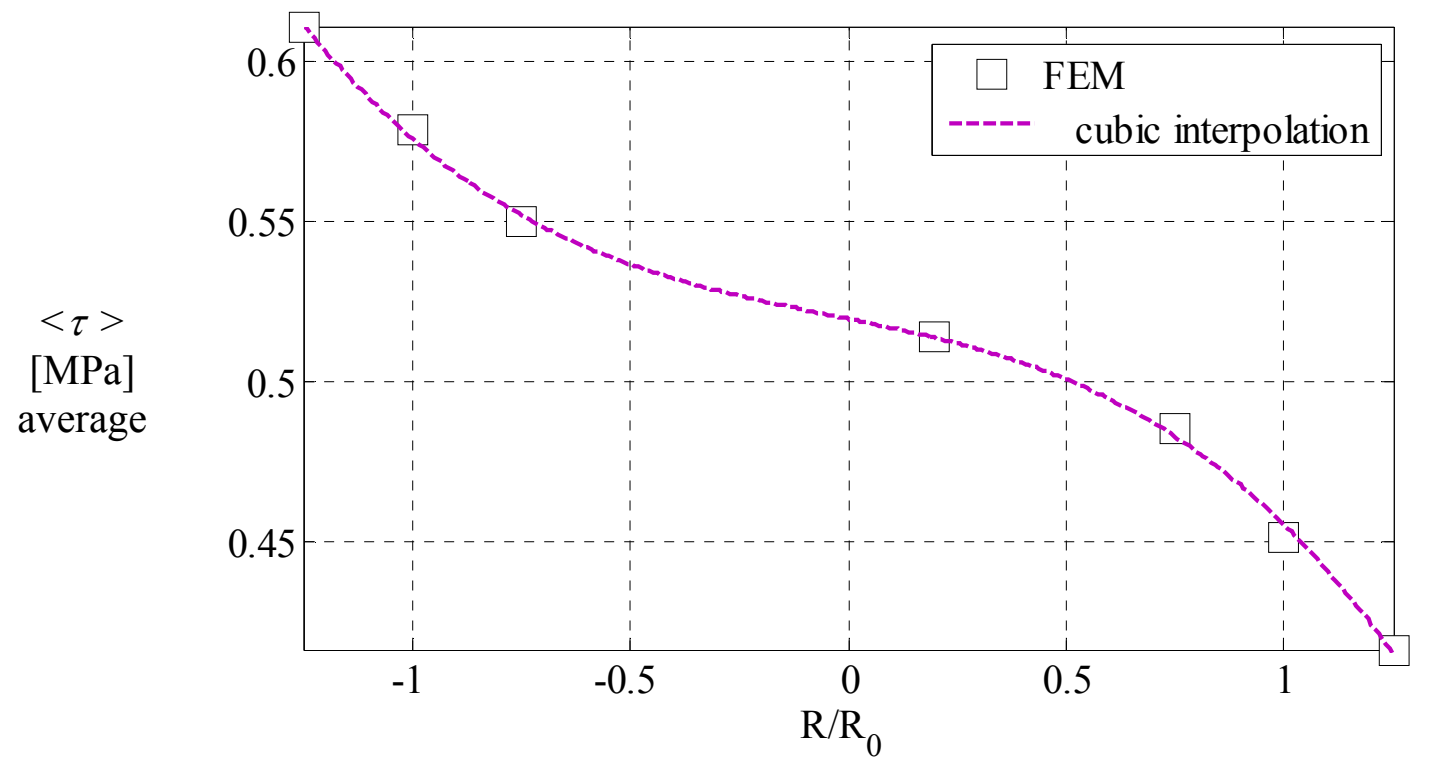

b)

Figure 16: Mean normal a) and tangential b) stresses acting over FRP-masonry interface as a function of normalized curvature radius (with square markers). A cubic spline (dashed line) is used for discrete data interpolation. 

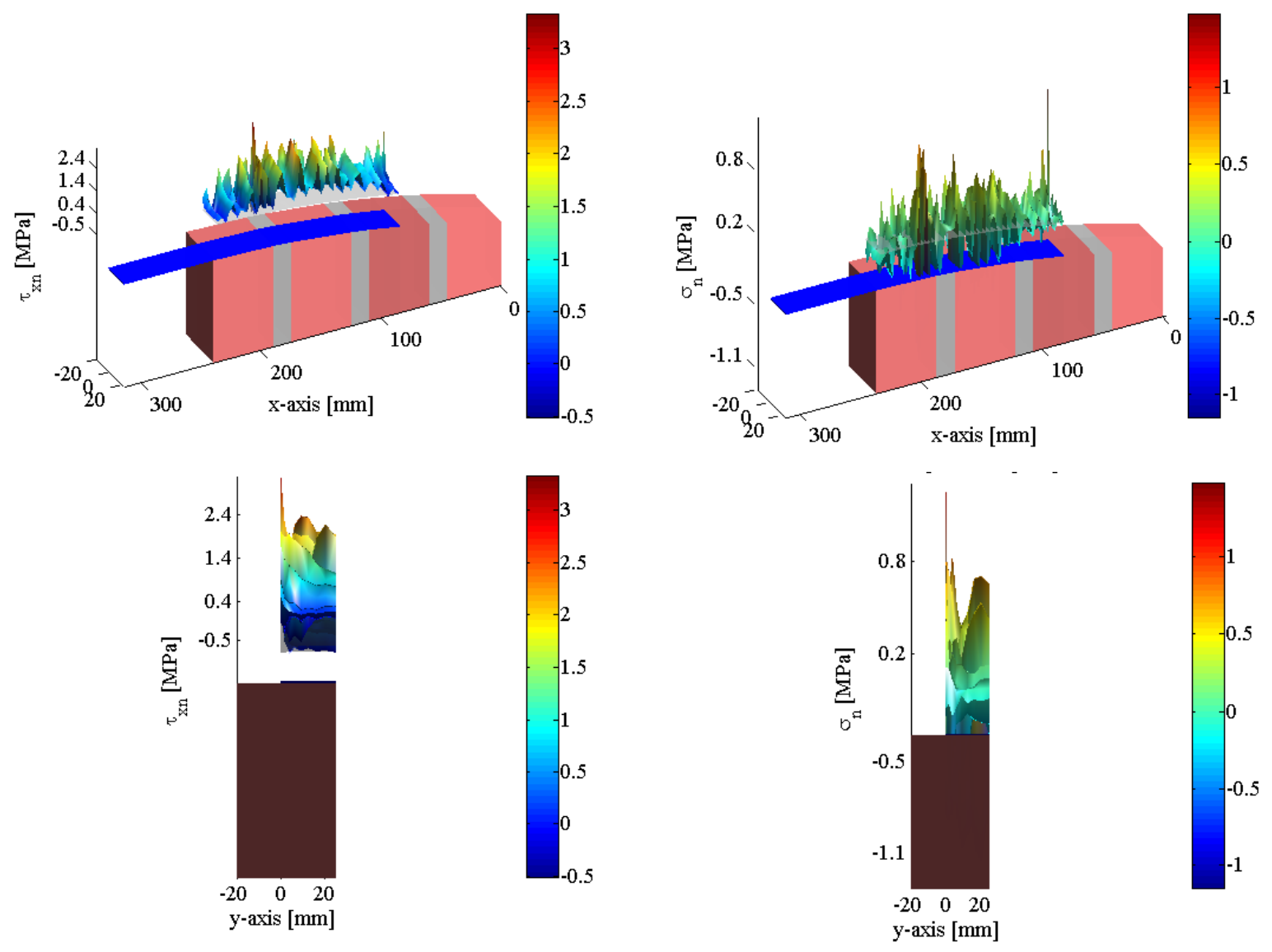

a)

b)

Figure 17: Concave specimen. Local tangential stress $\tau$ in a) and normal stress $\sigma_{n}$ in b) predicted by the FE model over the FRP-masonry interface at the peak. 

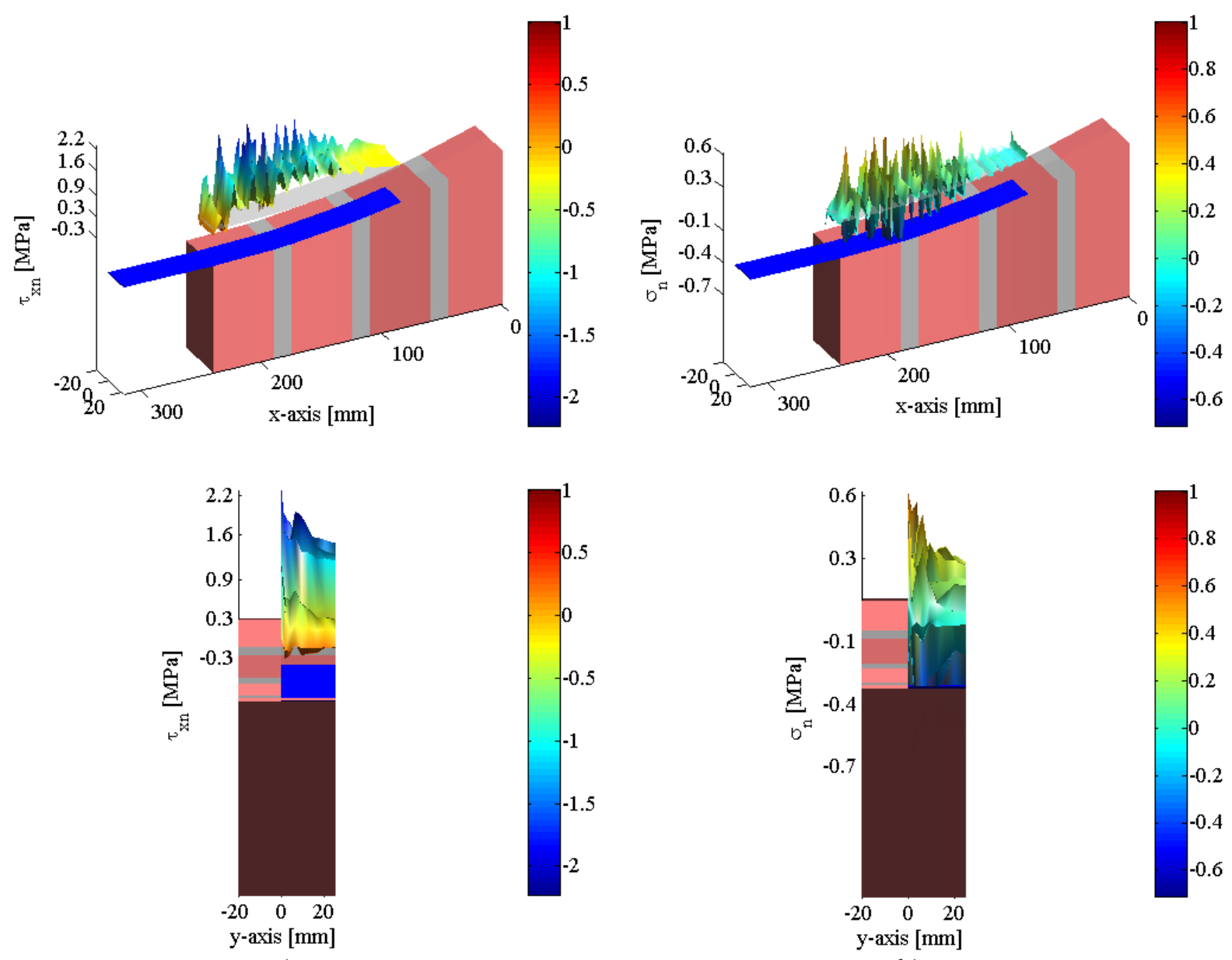

a)

b)

Figure 18: Convex specimen. Local tangential stress $\tau$ in a) and normal stress $\sigma_{n}$ in b) predicted by the FE model over the FRP-masonry interface at the peak. 


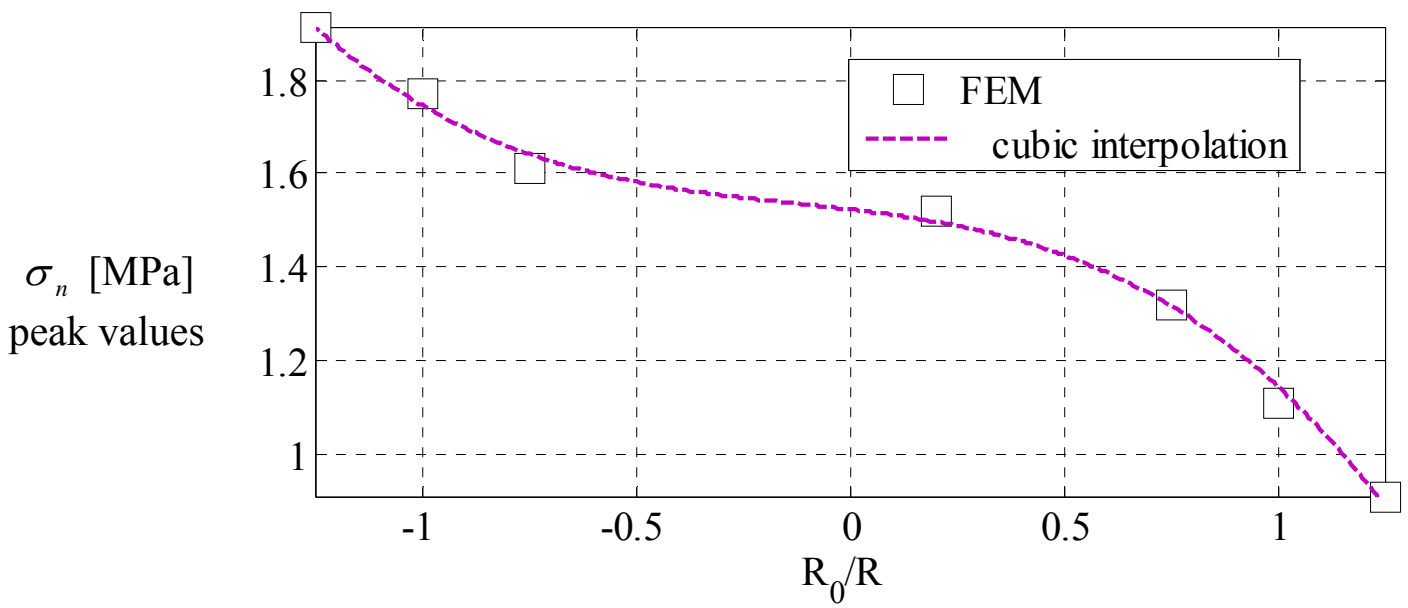

a)

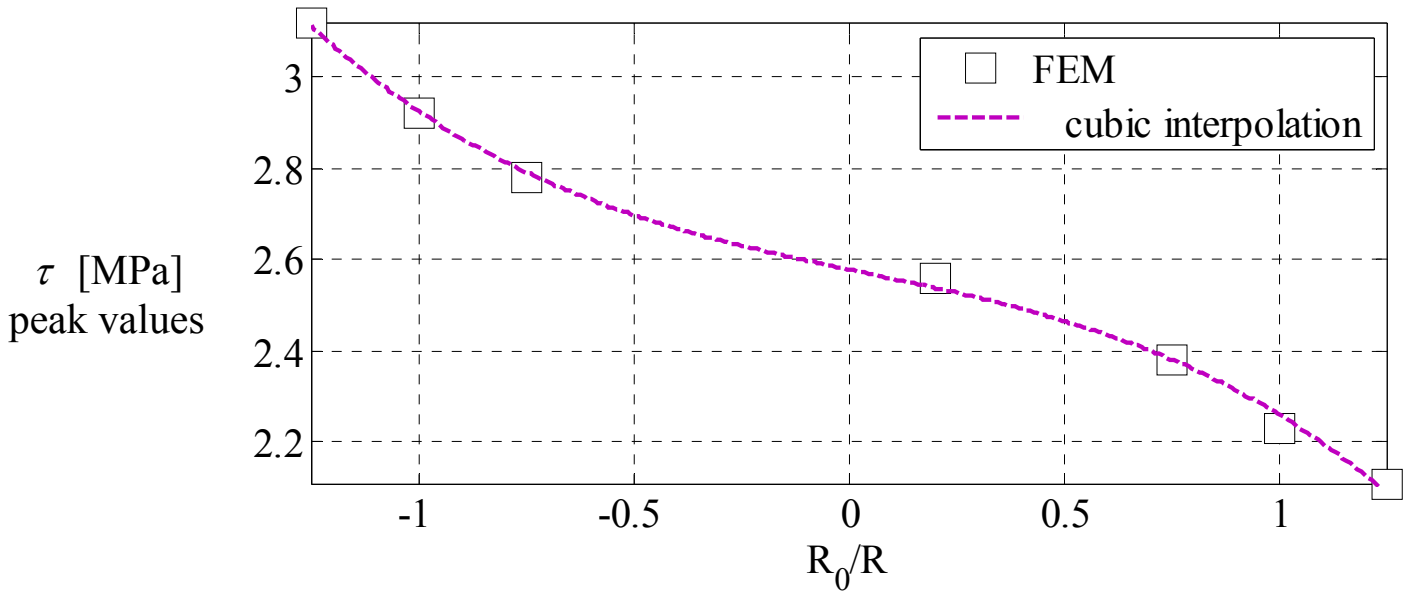

b)

Figure 19: Peak normal (a) and tangential (b) stresses (with square markers) acting over the FRPmasonry interface as a function of normalized curvature radius. A cubic spline (dashed line) is used for discrete data interpolation. 

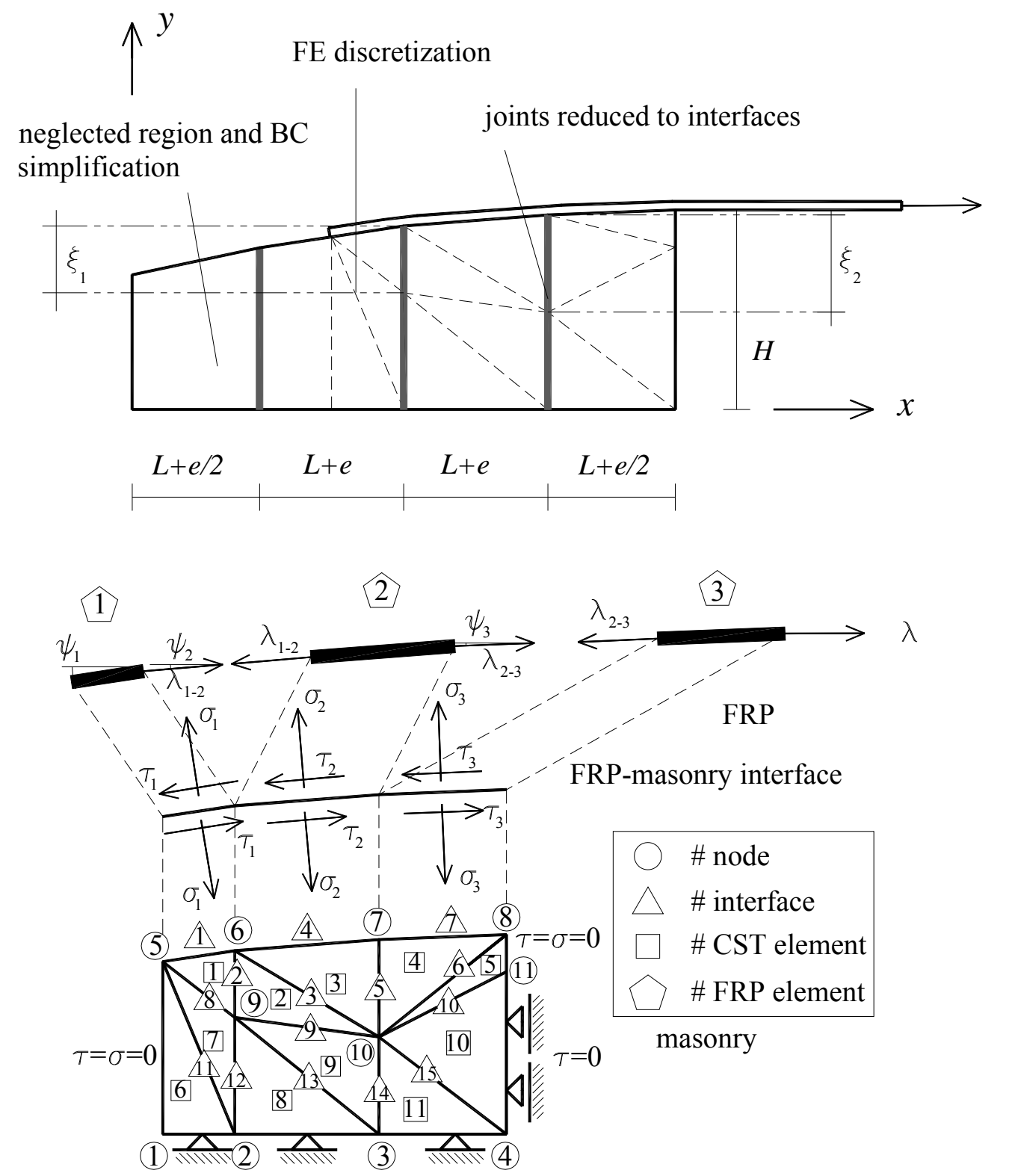

Figure 20: Analytical lower bound limit analysis model for the determination of delamination strength of reinforced masonry prisms. 


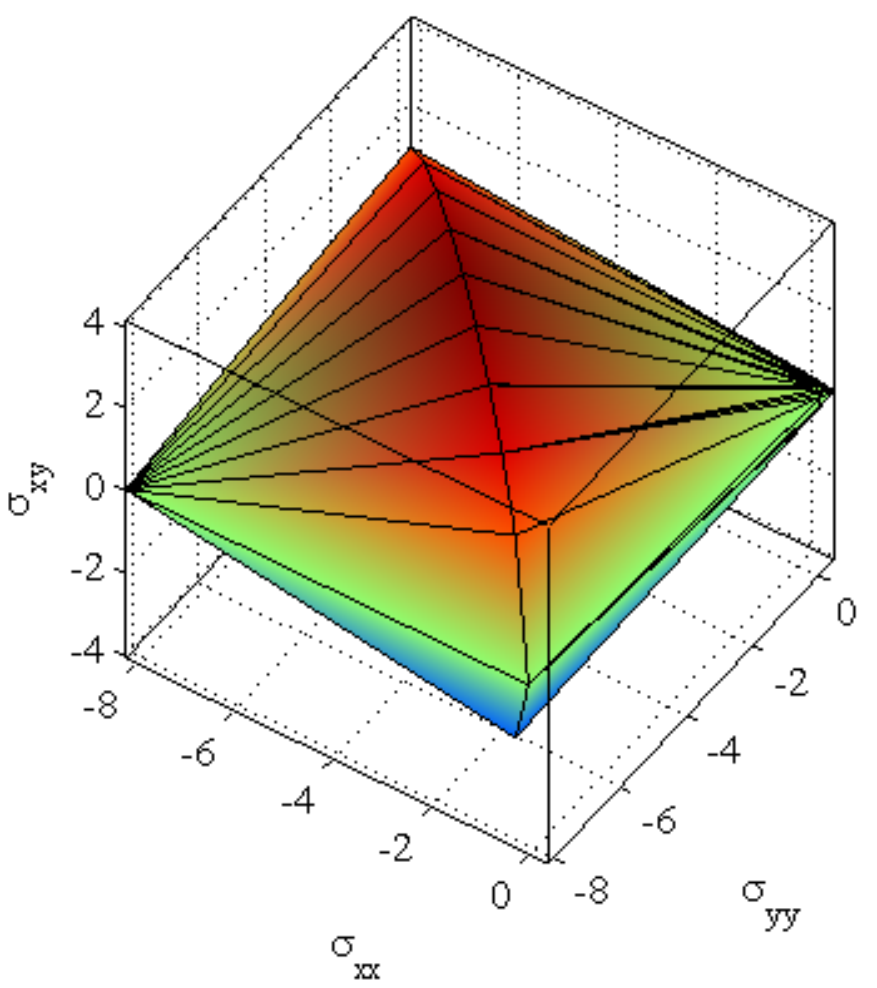

a)

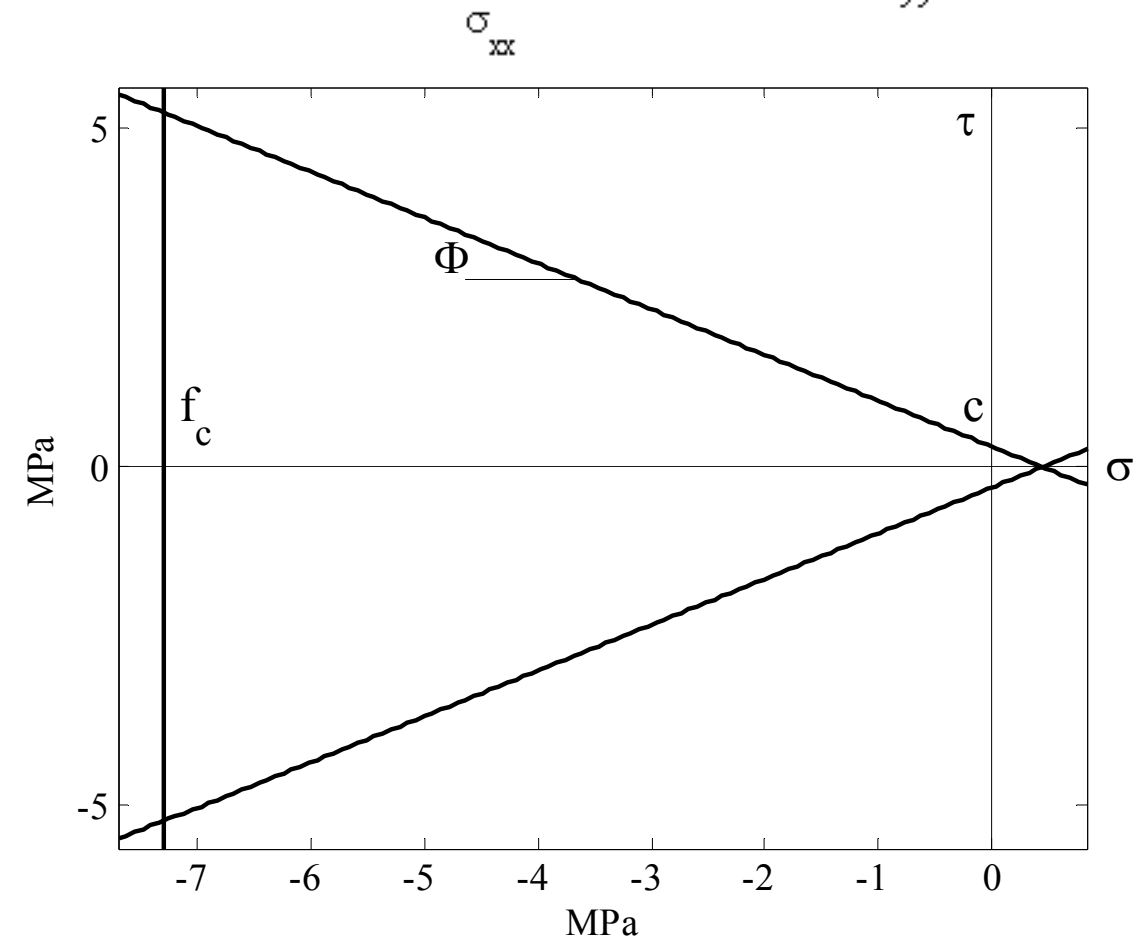

b)

Figure 21: Linearized failure surfaces adopted for brick (a) and mortar (b) in the "direct" lower bound limit approach. 


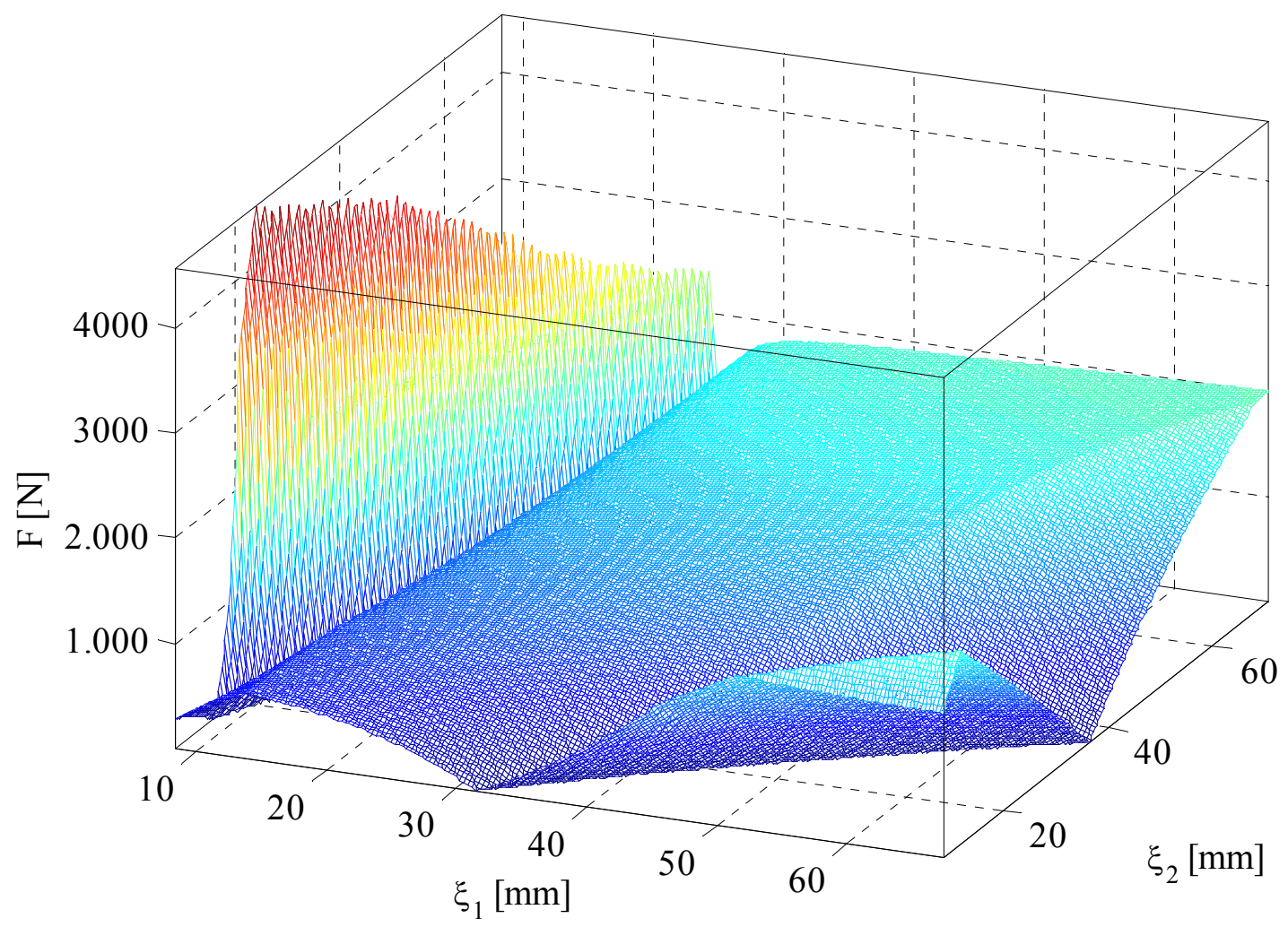

Figure 22: Peak load estimated by "direct" limit analysis method at varying $\xi_{1}$ and $\xi_{2}$ geometric parameters, $\mathrm{R}=\mathrm{R}_{0}$ concave configuration.

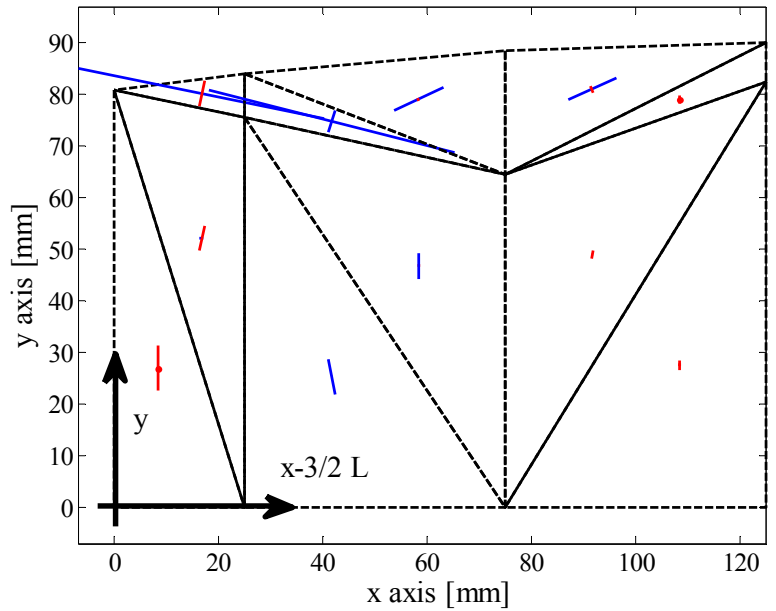

a) 


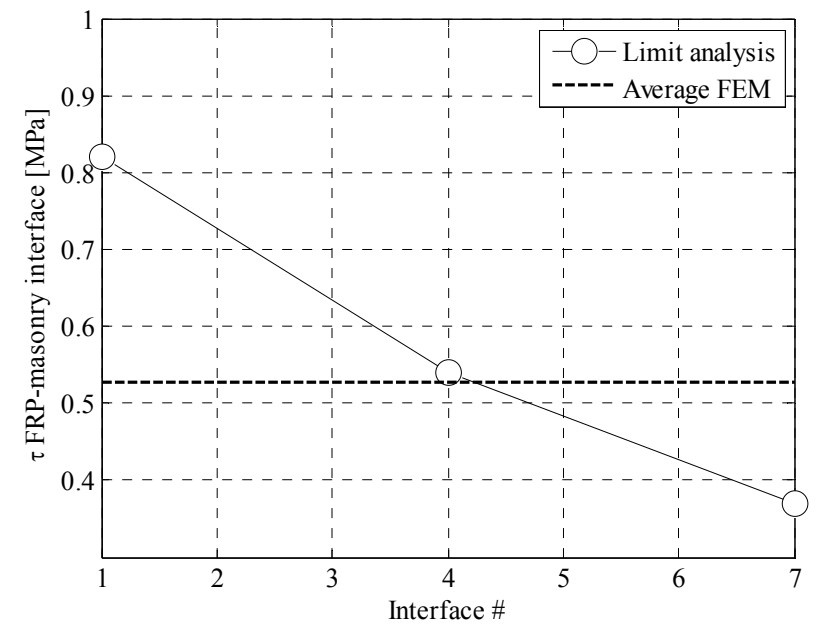

b)

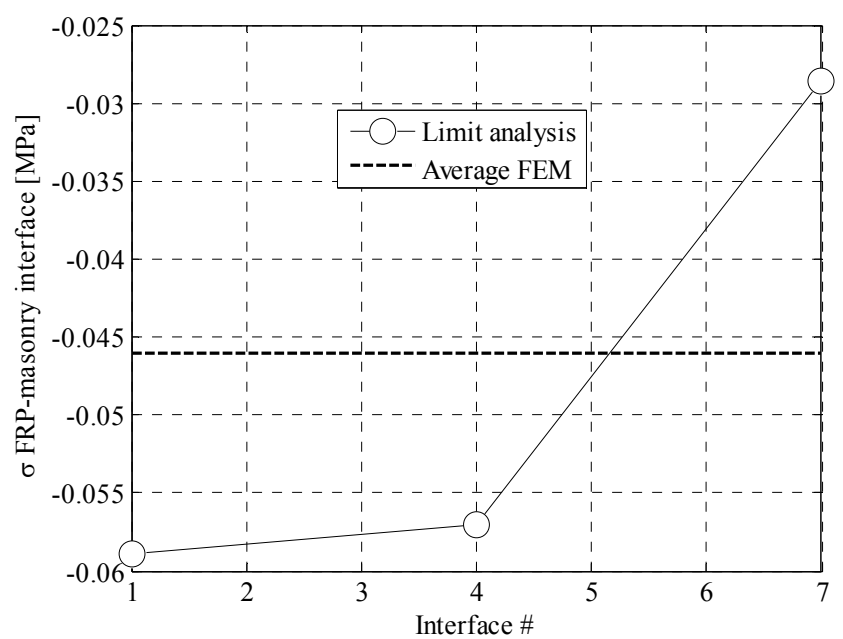

c)

Figure 23: Lower bound limit analysis procedure: a) Orientation and modulus of principal stresses in masonry elements at collapse;

b) tangential and c) normal traction over the FRP-masonry interface. 


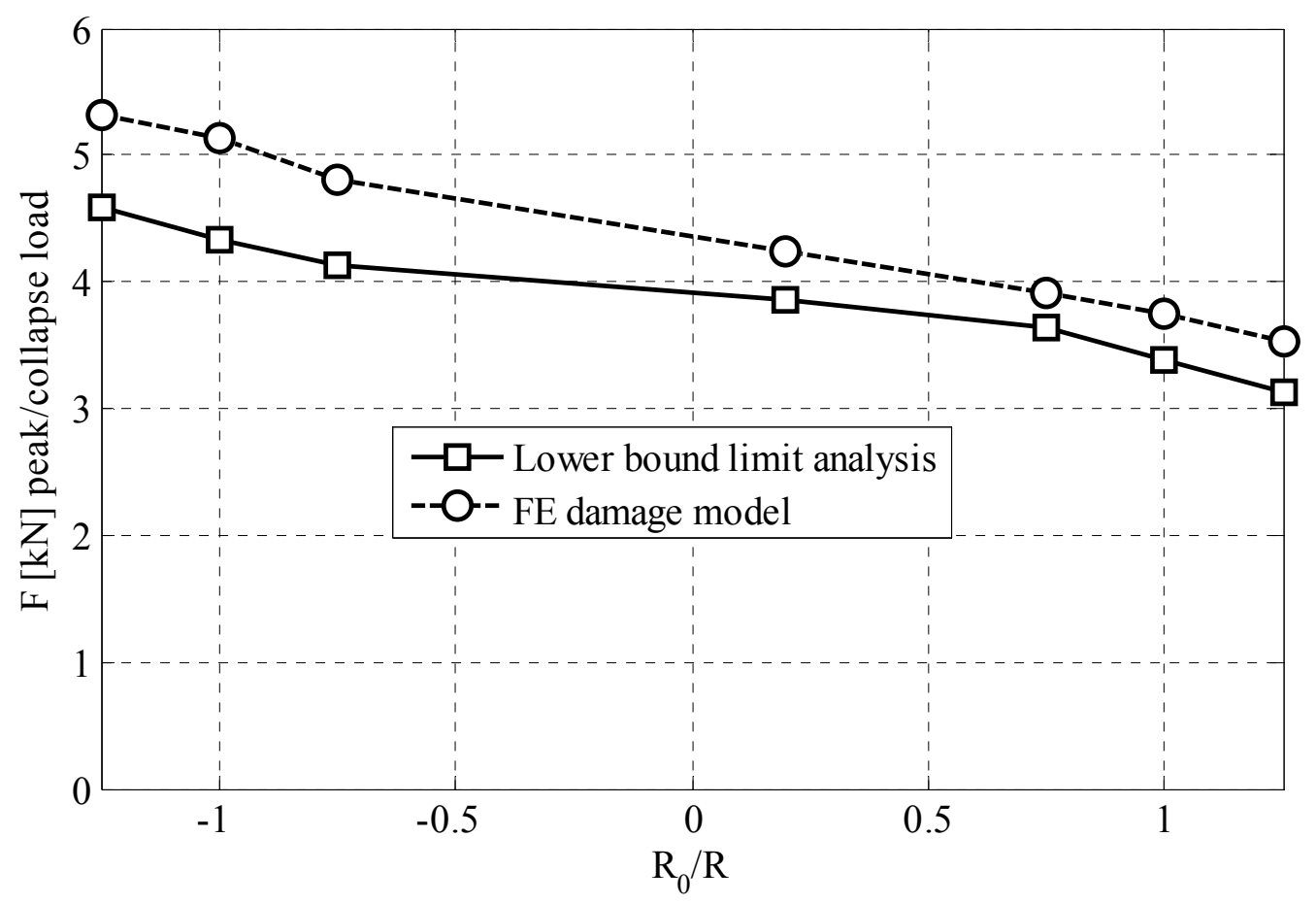

Figure 24: Collapse loading provided by the "direct" lower bond limit analysis approach, at varying the curvature radius. 
TABLES

Table 1. Mechanical properties of masonry constituents derived from the preliminary experiments.

\begin{tabular}{lcc|cc}
\hline & \multicolumn{2}{c|}{ Elastic } & \multicolumn{2}{c}{$\begin{array}{c}\text { Inelastic under } \\
\text { compression }\end{array}$} \\
\cline { 2 - 5 } Material & $\begin{array}{c}\mathrm{E}, \\
\left(\mathrm{N} / \mathrm{mm}^{2}\right)\end{array}$ & $v$ & $\begin{array}{c}\mathrm{f}_{\mathrm{c}} \\
\mathrm{N} / \mathrm{mm}^{2}\end{array}$ & $\begin{array}{c}\mathrm{G} / \mathrm{mm} \\
\mathrm{N} / \mathrm{mm}\end{array}$ \\
\hline brick & 3280 & 0.2 & 8.2 & 7 \\
mortar & 1800 & 0.2 & 7.3 & 12 \\
\hline
\end{tabular}


Table 2. Elastic and inelastic properties adopted for the brick and mortar in the heterogeneous damage model.

\begin{tabular}{|c|c|c|c|}
\hline $\begin{array}{c}\text { Model } \\
\text { parameter }\end{array}$ & Meaning & Brick & Mortar \\
\hline$E$ & Young modulus & $3280 \mathrm{MPa}$ & $1800 \mathrm{MPa}$ \\
\hline$v$ & Poisson ratio & 0.2 & 0.2 \\
\hline$a_{\mathrm{t} 0}$ & $\begin{array}{l}\text { parameter governing tensile } \\
\text { damage activation function } f_{t}\end{array}$ & 0.15 & 0.13 \\
\hline$a_{\mathrm{t} 1}$ & $\begin{array}{l}\text { parameter governing tensile } \\
\text { damage activation function } \mathrm{f}_{\mathrm{t}}\end{array}$ & $3.0 \mathrm{MPa}$ & $1.9 \mathrm{Mpa}$ \\
\hline$a_{\mathrm{t} 2}$ & $\begin{array}{l}\text { parameter governing tensile } \\
\text { damage activation function } \mathrm{f}_{\mathrm{t}}\end{array}$ & $1.3 \mathrm{MPa}^{2}$ & $0.58 \mathrm{MPa}^{2}$ \\
\hline$\left(\sigma_{\text {et }} / \sigma_{0 \mathrm{t}}\right)$ & $\begin{array}{l}\text { uniaxial stress at the elastic limit / } \\
\text { uniaxial peak stress, in tension }\end{array}$ & 0.8 & 0.8 \\
\hline$D_{0 \mathrm{t}}$ & tensile damage at peak & 0.1 & 0.1 \\
\hline$a_{\mathrm{c} 0}$ & $\begin{array}{l}\text { parameter governing compressive } \\
\text { damage activation function } f_{c}\end{array}$ & 0.0025 & 0.0036 \\
\hline$a_{\mathrm{c} 1}$ & $\begin{array}{l}\text { parameter governing compressive } \\
\text { damage activation function } f_{c}\end{array}$ & $1.5 \mathrm{MPa}$ & $2.4 \mathrm{MPa}$ \\
\hline$a_{\mathrm{c} 2}$ & $\begin{array}{l}\text { parameter governing compressive } \\
\text { damage activation function } f_{c}\end{array}$ & $53 \mathrm{MPa}^{2}$ & $2.1 \mathrm{MPa}^{2}$ \\
\hline$\left(\sigma_{\mathrm{ec}} / \sigma_{0 \mathrm{c}}\right)$ & $\begin{array}{l}\text { uniaxial stress at the elastic limit / } \\
\text { uniaxial peak stress, in compression. }\end{array}$ & 0.7 & 0.7 \\
\hline$D_{0 \mathrm{c}}$ & compressive damage at peak & 0.3 & 0.3 \\
\hline$G_{\mathrm{t}}$ & Dissipated energy in tension & $0.03 \mathrm{~N} / \mathrm{mm}$ & $0.058 \mathrm{~N} / \mathrm{mm}$ \\
\hline$G_{\mathrm{c}}$ & Dissipated energy in compression & $7 \mathrm{~N} / \mathrm{mm}$ & $12 \mathrm{~N} / \mathrm{mm}$ \\
\hline
\end{tabular}

